\title{
When Law is Good for Your Health: Mitigating the social determinants of health through access to justice
}

\begin{abstract}
Hazel Genn*
Abstract: Access to justice research over two decades has documented the health-harming effects of unmet legal needs. There is growing evidence of bidirectional links between law and health demonstrating that social and economic problems with a legal dimension can exacerbate or create ill health and, conversely that ill-health can create legal problems. Independently, social epidemiological research documents gross and widening inequalities in health, largely explained by social determinants such as income, housing, employment, and education. Although legal issues are embedded in most social determinants of health, law has been largely invisible in social determinants discourse, research and interventions. This article argues that legal services have an important role to play in mitigating many of the socio-economic determinants that disproportionately impact the health of low income and vulnerable groups. It describes the international practitioner-led movement of Health Justice Partnership through which lawyers work with healthcare teams to address the root causes of ill health rather than focusing on physical and psychological manifestations of negative social determinants. Finally, the article attempts to delineate the evolving field of health justice, advancing a transdisciplinary research agenda that could strengthen both public health and access to justice research by moving beyond the limitations of single discipline approaches. Noting the vigorous policy emphasis in law and health on prevention and partnership to address the twin challenges of access to justice and health inequalities, the article ends with a plea for policy coordination that acknowledges shared responsibility across government for improving the health of the public.
\end{abstract}

Key words: access to justice; unmet legal needs; social determinants of health; health inequalities; health justice partnership; medical-legal partnership; social prescribing; public health.

\section{Introduction: Law and Health}

Bringing together the conclusions of international socio-legal research on unmet legal needs and epidemiological research on the determinants of health, this article highlights the relatively unexplored links between law and health and suggests that socio-legal and health researchers have been investigating independently, through separate and distinct paradigms, the health effects of social problems with legal dimensions. Understanding that legal problems create or exacerbate ill health and that ill health creates problems for which the law provides solutions,

\footnotetext{
* Professor of Socio-Legal Studies and Executive Director of the Centre for Access to Justice, Faculty of Laws UCL. An early version of this paper was delivered as the 2018 Bentham Association Presidential Address. I am grateful to many people who have contributed in a range of ways to this article: Dr Matthew Appleby, Sarah Beardon, Firoza Dodhi, and Charlotte Woodhead for bibliographic and research assistance; The Legal Education Foundation for funding some of the underpinning research and in particular to Matthew Smerdon and Dr Natalie Byrom who have given exceptional practical and intellectual support; Professor Dame Anne Johnson, Professor Gwyn Bevan and Professor Sir Jonathan Montgomery for helpful comments and suggestions on earlier versions of this material; and Amanda Finlay, Suzie Forell and Sharon Witherspoon for insightful comments on a late draft of the article. Special thanks to Tessa Boyd Caine (CEO) and Suzie Forell (Research Director) of Health Justice Australia, and to Ellen Lawton (CEO) of the US National Center for Medical-Legal Partnership for their willingness to talk through ideas and issues. Any errors are mine.
} 
is a necessary step in understanding the links between law and health in the pursuit of improved public health and well-being.

This is an important time to be considering how the law can influence individual and population health. As the NHS marks its 70th anniversary, despite universal access to free health services, there are gross and widening differences in population health and well-being related to socio-economic status. Austerity measures and welfare reforms have increased pressures and economic instability for low income and disadvantaged groups. In these circumstances, free social welfare legal services can provide support to citizens facing the greatest social and economic challenges to avoid crisis. But these free legal services have been badly affected by the loss of legal aid provision and cuts in local authority budgets. ${ }^{1}$ With reduced community legal services for vulnerable patient groups experiencing complex sociolegal issues, there is evidence that these problems are over-spilling into NHS General Practice, as GPs become the last source of free professional advice in the community. While NHS GPs struggle to meet the increased demand of an ageing population and rise in multi-morbidity, ${ }^{2} \mathrm{a}$ high proportion of consultations concern either non-medical social problems or medical problems with a social cause, the top four being the socio-legal issues of family breakdown, employment problems, access to welfare benefits, and inadequate housing. ${ }^{3}$ Patient demand for such "non-health" work has been identified as a contributing factor to increased general practice pressures ${ }^{4}$ exerting additional strain on GPs (particularly those in deprived areas) and exacerbating health inequalities. ${ }^{5}$

The role that law plays in health is a relatively novel area of interest for legal and health practitioners and researchers Although law has an influence on health and well-being at several different levels, and although public health theory acknowledges causal connections between social problems with a legal dimension and morbidity, ${ }^{6}$ there has been little focus on law in the social determinants of health literature other than at the broadest legislative level. There is, however, growing interest in the potential for integrating health and legal services to mitigate health inequalities, improve health and well-being and reduce some of the current pressures on the health system.

In the context of contemporary access to justice challenges and tenacious health inequalities, this article argues that legal services can mitigate many of the socio-economic determinants that disproportionately impact the health of low income and vulnerable groups by securing critical entitlements, by improving living conditions, by avoiding or diverting

\footnotetext{
${ }^{1}$ L Logan Green and J Sandbach, Justice in Free Fall: Impact of Changes to Civil Legal Aid (Legal Action Group, December 2016) <www.lag.org.uk/article/201911/justice-in-free-fall--a-report-on-the-decline-of-civil-legal-aidin-england-and-wales> accessed 2 March 2019.

2 Spotlight on the 10 High Impact Actions, (Royal College of General Practitioners, 2018), p6. swww.rcgp.org.uk/policy/general-practice-forward-view/spotlight-on-the-10-high-impact-actions.aspx> accessed 2 March 2019.

${ }^{3}$ Advice in Practice: Understanding the Effects of Integrating Advice in Primary Care Settings, (Citizens Advice and Royal College of General Practitioners, June 2018) <https://www.citizensadvice.org.uk/global/public/impact/understanding\%20the $\% 20$ effects\%20of $\% 20$ advice $\% 2$ 0in\%20primary\%20care\%20settings_research\%20report\%20\%28final\%29.pdf $\geq$ accessed 2 March 2019, 7.

${ }^{4}$ B Baird, A Charles, M Honeyman, D Maguire and P Das, Understanding Pressures in General Practice. (The King's Fund, May 2016). <www.kingsfund.org.uk/sites/default/files/field/field_publication_file/UnderstandingGP-pressures-Kings-Fund-May-2016.pdf> accessed 2 March 2019.

${ }^{5}$ The Impact of the Economic Downturn and Policy Changes on Health Inequalities in London. (Institute of Health Equity 2012) <www.instituteofhealthequity.org/resources-reports/the-impact-of-the-economic-downturn-andpolicy-changes-on-health-inequalities-in-london/the-impact-of-economic-downturn.pdf $>$ accessed 2 March 2019.

${ }^{6}$ E Tobin-Tyler, KN Conroy, C-M Fu and M Sandel, 'Housing: The Intersection of Affordability, Safety and Health', in ET Tyler, E Lawton, KN Conroy, M Sandel and B Zuckerman (eds), Poverty, Health and Law (Carolina Academic Press 2011).
} 
threats to employment, to family security, and many other health-harming risks. It proposes an agenda for service innovation, research evaluation and policy development that might make a conspicuous contribution to improving population health and mitigating health inequalities. It does this in several stages.

The article starts by considering the theoretical levels at which law influences health, and then moves on to a discussion of what socio-legal research on legal needs has revealed about the links between everyday legal problems and ill health. The next part explains what social epidemiological research has established about the social determinants of health and health differences. The following part describes a grass roots innovation involving healthcare professionals working in partnership with social welfare legal services to mitigate health inequalities and considers the extant evidence for the benefits of integrated legal and health services for patients, healthcare professionals and service demand. The final part describes the emerging field of 'health justice', making the case for transdisciplinary research collaboration to support cross-sector policy development and practice innovation that could transform service delivery and improve health and well-being among disadvantaged and vulnerable groups.

\section{The Role of Law in Health}

Law is arguably one of the most important social determinants of health, critically influencing the framework in which individuals and populations live, face disease and injury and eventually die. ${ }^{7}$ Law provides protective rights and entitlements to shield the vulnerable from most of the factors known to harm health and well-being. Legal practitioners work across the entire range of social determinants to mitigate negative health impacts including low income, inadequate housing, homelessness, access to educational opportunities, employment security, family breakdown, discrimination, domestic and elder abuse. One can articulate the role of law in health at three different levels.

At the macro level, law-making promotes individual and population level health benefits, through implemented broad policy change such as smoke-free laws, alcohol pricing and the introduction of sugar tax. A recent example is the Public Health (Wales) Act 2017 giving statutory force to the concept of 'health in all policies', requiring public bodies to undertake health impact assessments of new policies. Also, at the macro level the courts, through judicial decisions, directly influence medical practice and standards of care.

At the meso or local level, a wide range of institutional and business policies and practices affect health. Law can ensure that public bodies comply with statutory responsibilities in relation to decision-making around entitlements and access to services and goods designed to enhance health by protecting low income and vulnerable groups.

At the micro individual level, the law 'prescribes' measures to ameliorate inequality and social exclusion. But these legal protections often fail to benefit the most disadvantaged groups experiencing the greatest burden of ill health because people do not receive or access the benefits, goods and conditions to which they are entitled. Many of the health issues experienced by patients result from unenforced laws or incorrect denial of critical services, leading to preventable poor health outcomes. For these individuals and families, the provision of social welfare legal advice can have preventive and remedial impact in crisis situations such as threatened eviction, loss of income, threatened employment termination, family breakdown,

\footnotetext{
${ }^{7}$ W Parmet, L Smith and M Benedict, 'Social Determinants, Health Disparities and the Role of Law' in TobinTyler and others (eds), Poverty, Health and Law (n 6).
} 
and chronic stressors such as inadequate benefits, inappropriate social housing, or domestic violence.

Despite its significance for health, law seems to have been relatively invisible in most health discourse and social epidemiological research on the determinants of health. The medical and public health sectors generally have not looked to the legal sector as a vehicle for the solution of health problems. The role of law as a mediator of the nation's health is one of the least well recognised, researched or understood. And yet it has been powerfully argued that 'legal issues are embedded in most social determinants of health, making lawyers a necessary part of any strategy to address them, whether at the individual, local, or national level'. ${ }^{8}$

Public health theory recognises the connections between social issues with a legal dimension and ill health, ${ }^{9}$ but has tended to focus on population-wide or national level activities such as developing and implementing health laws ${ }^{10}$ rather than the potential of legal services to influence health at the individual and meso level. On the legal side, to the extent that sociolegal researchers have paid empirical attention to the intersection of law and health, the focus has been on the ethics of medical research and critical care, medical decisions, court oversight of treatment decisions, rationing processes, and clinical negligence. A recent review of largely USA socio-legal research in the health policy field notes that despite the foundation of the field of 'law and society' in policy-oriented studies and its long-standing concern with issues of inequality, 'there has been no systematic engagement with health policy within sociolegal scholarship'. ${ }^{11}$ However, one area of socio-legal research that has begun to focus on the connection between law and health is the field of access to justice and, in particular, research on unmet legal needs.

\section{Access to Justice and Health}

\section{A. Access to Justice and Legal Needs}

Legal needs are not currently part of the language of healthcare, nor is legal care a tool in the toolbox healthcare team members use to treat patients or address population health. The connection between legal needs and health is invisible in the provision of healthcare. ${ }^{12}$

The permeation of law into all aspects of business, social and family life means that citizens frequently face social problems that have a legal dimension - social problems that are justiciable to the extent that the law provides a remedy or some form of redress, whether or not this is known or understood by those experiencing the problem. ${ }^{13}$ Examples are problems about income maintenance, housing, employment, education, care of children, immigration, security, and so on. In this way, social problems or social needs can become legal needs when the law

\footnotetext{
${ }^{8}$ J Teitelbaum and E Lawton, 'The Roots and Branches of the Medical-Legal Partnership Approach to Health: From Collegiality to Civil Rights to Health Equity' (2017) 17 Yale Journal of Health Policy, Law, and Ethics 5.

9 Tobin-Tyler and others, 'Housing: The Intersection of Affordability, Safety and Health' (n 6).

${ }^{10}$ S Burris, M Ashe, D Levin, M Penn and M Larkin, 'A Transdisciplinary Approach to Public Health Law: The Emerging Practice of Legal Epidemiology’ (2016) 37 Ann Rev Public Health 135.

${ }^{11}$ SR Levitsky, 'Integrating Law and Health Policy' (2013) 9 Ann Rev Law Soc Sci 33, P35.

12 <https://kresge.org/sites/default/files/Uploaded\%20Docs/Medical-Legal-Partnership-toolkit-phase-1.pdf> accessed 2 March 2019.

${ }^{13}$ H Genn, Paths to Justice: What People Think and Do About Going to Law (Hart Publishing 1999).
} 
provides a right or benefit that would alleviate or attenuate the social need, but the law cannot be mobilized, for example, because of lack of knowledge or opportunity to take advantage of a legal process or remedy. In these situations, access to social welfare legal advice and assistance may be an essential element in securing entitlements and critical services and ultimately social justice. ${ }^{14}$

Access to justice may relieve poverty and lift people out of social exclusion. Identifying the incidence of legal needs within the population supports effective access to justice policy by providing evidence that can help target available resources and free legal services on geographical and subject areas of greatest legal need. Over the past 25 years, some 40 largescale national legal needs surveys have been conducted around the world in at least 22 separate jurisdictions ${ }^{15}$ providing a rich understanding of public experience of justiciable problems, whether and how such problems are resolved, and of the extent of unmet legal need and its consequences.

Despite differences in methodology, these international legal needs surveys have produced some consistent broad findings. The most important of these is that although justiciable problems are ubiquitous, affecting all social groups, ${ }^{16}$ experience of such problems is not randomly distributed across populations, but instead associated with disadvantage. Low income, socially excluded and vulnerable groups report both higher rates of experience of justiciable problems and a greater incidence of negative consequences from such events. ${ }^{17}$ Surveys have also identified the phenomenon of problem clustering in which certain kinds of justiciable problem occur together with others, typically such as domestic violence which is associated with relationship breakdown, unemployment and debt problems. ${ }^{18}$

It has been suggested that the reasons for the link between justiciable problem experience and disadvantage are first, that certain problems are peculiar to disadvantage - an obvious example being welfare benefits - and that second, disadvantaged people have fewer resources to draw on and probably are less able to avoid or mitigate problems. ${ }^{19}$

Because advice and assistance in dealing with justiciable problems is often so important, legal needs surveys have sought to map the various 'paths to justice' that people take. Although theoretically there are many such paths, surveys show that often, and particularly among disadvantaged groups, people do nothing to resolve their problem because they are unaware of their rights, ${ }^{20}$ do not know what to do or where to go for help, or do not feel that a resolution is possible - reasons often conveying 'a rather negative and powerless quality'. ${ }^{21}$ Those who do seek assistance frequently approach inappropriate sources, such as the police or GPs who

\footnotetext{
${ }^{14}$ JM Stein, The Future of Social Justice in Britain: A New Mission for The Community Legal Service (2001) CASE Discussion Paper Series 48 <https://core.ac.uk/download/pdf/93906.pdf> accessed 2 March 2019.

${ }_{15}$ P Pleasence, Legal Need and Legal Needs Surveys: A Background Paper (Open Society Justice Initiative, Open Society Foundation, June 2016).

${ }^{16}$ Genn (n 13) 22-31.

${ }^{17}$ R Sandefur, 'What We Know and Need to Know About the Legal Needs of The Public' (2016) 67 South Carolina Law Review 443.

${ }^{18}$ Genn (n 13) 31-36. See also P Pleasence, NJ Balmer, A Buck, A O'Grady and H Genn, 'Multiple Justiciable Problems: Common Clusters and Their Social and Demographic Indicators' (2004) 1 Journal of Empirical Legal Studies 301

${ }^{19}$ P Pleasence, NJ Balmer and P Chapman, Legal Needs Surveys and Access to Justice (OECD and Open Society Justice Initiative 2018).

${ }^{20}$ Recent legal needs survey findings from England \& Wales indicate that levels of understanding of legal rights and responsibilities are very low (and, indeed, sometimes systematically erroneous), see P Pleasence, NJ Balmer and C Denvir, How People Understand and Interact with The Law (The Legal Education Foundation 2015). < https://www.thelegaleducationfoundation.org/wp-content/uploads/2015/12/HPUIL_report.pdf> accessed 3 March 2019.

${ }^{21}$ Genn (n 13) 70.
} 
are unlikely to be in a position to provide relevant and constructive advice on individual problems. The standard response is to refer people elsewhere, but studies have shown that, while well-intentioned, this practice is ultimately often unhelpful and may be counterproductive. The phenomenon identified as 'referral fatigue' reveals that the more often a person is referred to another source of assistance, the less likely they are to visit that source, thus continuing to leave legal needs unmet. ${ }^{22}$

\section{B. Health-harming legal needs}

[V]irtually all legal needs (ranging from housing issues to domestic violence) are directly or proximally connected to health status. ${ }^{23}$

Legal needs surveys have consistently found that justiciable problems substantially affect the lives of those facing them, bringing about or following on from broader social problems. ${ }^{24}$ People experiencing poor mental or physical health, those on low income and those with other vulnerabilities disproportionately have legal needs relating to accessing welfare benefits, longterm indebtedness, ${ }^{25}$ and adverse housing circumstances. ${ }^{26}$ They are also more likely to have difficulty accessing support and advice for such issues. ${ }^{27}$ If legal problems are left unaddressed, they can cause a cascade of consequences that can ultimately push people into poverty or other harms such as family breakdown, and homelessness. ${ }^{28}$

Some legal needs surveys have recently begun a more sophisticated exploration of the relationship and impact of justiciable problems on health and other aspects of life. Of relevance for the present discussion is the developing interest in the bidirectional link between legal problems and morbidity/disability. Social issues with a legal dimension can create or exacerbate ill health and, conversely ill-health can create legal problems. ${ }^{29}$

There is mounting evidence that facing social issues with a legal dimension can cause stress-related or physical ill health and a cascade of social, family and employment crises in

\footnotetext{
${ }^{22}$ P Pleasence, A Buck, N Balmer, A O’Grady, H Genn and M Smith, Causes of Action: Civil Law and Social Justice (The Stationery Office 2004) 77.

${ }^{23}$ B Zuckerman, M Sandel, E Lawton and S Morton, 'Medical-legal partnerships: transforming health care' (2008) 372 The Lancet 1615, 1616.

${ }^{24}$ Cf Pleasence and others (n 19).

${ }^{25}$ C Fitch, S Hamilton, P Bassett and R Davey, 'The Relationship Between Personal Debt and Mental Health: A Systematic Review' (2011) 16 Mental Health Review Journal 153; NJ Balmer, P Pleasence, A Buck and H Walker, 'Worried Sick: The Experience of Debt Problems and their Relationship with Health, Illness and Disability' (2005) 5 Social Policy and Society 39.

${ }^{26}$ R Tunstall, M Bevan, J Bradshaw, K Croucher, S Duffy, C Hunter, A Jones, J Rugg, A Wallace and S Wilcox, The Links Between Housing and Poverty: An Evidence Review (Joseph Rowntree Foundation 2013) <www.york.ac.uk/media/chp/documents/2013/poverty-housing-options-full.pdf> accessed 2 March 2019.

${ }^{27}$ D Finn and J Goodship, Take-Up of Benefits and Poverty: An Evidence and Policy Review (Centre For Economic \& Social Inclusion 2014) <www.learningandwork.org.uk/wp-content/uploads/2017/01/benefit-takeup-final-report-inclusion-proofed-june-2014-pdf.pdf> accessed 2 March 2019; P Pleasence, NJ Balmer and A Buck, 'The Health Cost of Civil - Law Problems: Further Evidence of Links Between Civil - Law Problems and Morbidity, and The Consequential Use of Health Services' (2008) 5 Journal of Empirical Legal Studies 351; and also, for example, P Pleasence and NJ Balmer, Health Inequality And Access To Justice: Young People, Mental Health And Legal Issues (Youth Access 2015), < https://www.thelegaleducationfoundation.org/wpcontent/uploads/2015/12/SDYPMH_report.pdf > accessed 2 March 2019.

${ }^{28}$ P Prettimore, Poverty and Legal Problems in Jordan: Defining the Relationship (2015) MENA Knowledge and Learning Quick Notes Series No 150 <https://openknowledge.worldbank.org/handle/10986/22734> accessed 2 March 2019.

${ }^{29}$ Tobin-Tyler and others (n 6) have pointed to a vicious circle of vulnerability involving health problems, inability/disruption to work, loss of income, non-payment of rent, eviction and homelessness, 236.
} 
previously healthy people. The England and Wales Civil and Social Justice Survey 2006-2009 found that half of its 10,000 respondents who had experienced a legal problem suffered an adverse consequence, including physical and mental health problems. Of those suffering health problems some $50-80 \%$ had presented to health services. ${ }^{30}$ Similarly, Australian legal needs data show strong links between the experience of legal problems and long-term illness/disability, with a general strengthening of association as severity of illness/disability increases - particularly so in the case of mental impairment. ${ }^{31}$ The most recent global study of the impact of legal problems carried out by the World Justice Project in 2018 found that about one in three people with justiciable problems became physically or mentally ill as a result. ${ }^{32}$

A recent secondary analysis of legal needs data found that respondents with mental health problems experienced significantly more legal problems than other respondents and were more likely to report adverse consequence such as becoming homeless, unemployed, ill, suffering relationship breakdown, and so on. Of those legal problems that led to stress-related ill health, more than half resulted in respondents consulting a GP, doctor or other health care professional. ${ }^{33}$

How is it, then, that legal problems - or social issues with a legal dimension - come to harm health? It is known that the social and material conditions of daily life act through the mind - 'psychosocial pathways' - to affect wellbeing and health. ${ }^{34}$ Stressors experienced repeatedly or over a long period of time, including stressful living and working conditions, are associated with high blood pressure, development of diabetes, and ischemic heart disease. In simple terms, being 'stressed out' - what is referred to as 'allostatic overload' in the public health literature - makes people ill. ${ }^{35}$ So stress has a direct effect on health, but it can also affect health indirectly, for example, through influencing health behaviour. ${ }^{36}$ There is evidence that people in lower socio-economic groups experience greater chronic stress exposure than more

\footnotetext{
${ }^{30}$ NJ Balmer, P Pleasence and A Buck, 'Psychiatric Morbidity and People's Experience of and Response to Social Problems Involving Rights' (2010) 18 Health and Social Care in The Community 588.

${ }^{31}$ C Coumarelos, P Pleasence and Z Wei, 'Law and Disorders: Illness/Disability and the Experience of Everyday Problems Involving Law' (2013) Law and Justice Foundation, Justice Issues, Paper 17 <www.lawfoundation.net.au/ljf/site/templates/updatingjustice/\$file/uj_22_law_and_disorders_working_paper_f inal.pdf > accessed 2 March 2019, 16.

32 World Justice Project, Global Insights into Access to Justice (2018) <https://worldjusticeproject.org/ourwork/wjp-rule-law-index/special-reports/global-insights-access-justice $\geq$ accessed 2 March 2019 (surveys of 46,000 people in 45 Countries).

${ }^{33}$ NJ Balmer and P Pleasence, Mental Health, Legal Problems And The Impact Of Changes To The Legal Aid Scheme: Secondary Analysis of 2014-2015 Legal Problem Resolution Survey Data (February 2018) <www.mind.org.uk/media/23586755/balmer-and-pleasence-lprs-analysis-for-mind-110418.pdf> accessed 2 March 2019.

${ }^{34}$ R Bell, Psychosocial Pathways and Health Outcomes: Informing Action on Health Inequalities (Public Health England, September <https://assets.publishing.service.gov.uk/government/uploads/system/uploads/attachment_data/file/647709/psyc hosocial_pathways_and_health_equity.pdf > accessed 2 March 2019, 11.

35 'Allostatic load' is defined as the cost of chronic exposure to raised or fluctuating endocrine or neural responses resulting from prolonged or repeated challenges that the individual experiences as stressful. Bruce S. McEwen, 'Allostasis and Allostatic Load: Implications for Neuropsychopharmacology' (2000) 22(2) Neuropsychopharmacology 108.

${ }^{36}$ NE Adler and K Newman, 'Socioeconomic disparities in health: Pathways and policies. Inequality in education, income, and occupation exacerbates the gaps between the health "haves" and "have-nots" (2002) 21(2) Health Affairs 60, 65. See also, S Mullainathan and E Shafir, Scarcity: Why Having Too Little Means So Much (Macmillan 2013).
} 
advantaged groups and these differences in stress exposure may result in differing biologic risk for diseases. ${ }^{37}$

Also, of considerable significance is the increasing attention being paid to the impact of early life experiences on health throughout the life course and in perpetuating cycles of deprivation. People who have been exposed to adverse childhood or adolescent experiences (ACEs) are likely to have more physical and mental health problems as adults than those spared such experiences. ${ }^{38}$ The description of ACEs and consequences point clearly to the health impacts of social issues in need of legal solutions. ${ }^{39}$ ACEs may be direct, such as psychological, physical, sexual abuse, and neglect, and they can also be indirect through poor living conditions or exposure to substance abuse, parental violent conflict or mental health difficulties. Children growing up in chronically stressful environments can suffer harm to the development of their nervous, endocrine and immune systems, ultimately leading to long-term damage that renders them more susceptible to illness and engaging in health harming behaviour such as substance abuse.

Research on the impact of legal needs highlights a critical point in the link between law and health - and that is the very clear overlap between groups needing legal and health services. Those with the most complex needs for legal services tend to be the patients with the most complex needs for health services, and all generally dealing with significant social disadvantage. It is not, therefore, a particularly difficult logical step to imagine the value of integrated services that both resolve health harming legal needs and secure rights and entitlements that would alleviate social needs that harm health. This issue is discussed in more detail in part 5 below.

\section{The Value of Legal Assistance and the Impact of LASPO 2012}

For low income and disadvantaged groups, legal assistance is an essential tool for successfully resolving social problems with a legal dimension. ${ }^{40}$ Providing free legal services delivers tangible benefits to users and saves social and financial costs to the public purse, for example, by securing needed welfare benefits, by preventing domestic violence, avoiding homelessness, or preventing loss of employment. Evidence suggests that the provision of legal advice is the only service that reduces domestic violence. ${ }^{41}$ Automatic provision to cancer patients of advice on financial issues and employment rights supports recovery and retains employees living with

\footnotetext{
${ }^{37}$ J Siegrist and M Marmot, 'Health Inequalities and The Psychosocial Environment—Two Scientific Challenges' (2004) 58 Social Science \& Medicine 1463.

${ }^{38}$ MA Bellis and others, 'Measuring mortality and the burden of adult disease associated with adverse childhood experiences in England: a national survey' (2015) 37 J Public Health 445.

${ }^{39}$ VJ Felitti and others, 'Relationship of Childhood Abuse and Household Dysfunction to Many of The Leading Causes of Death in Adults: The Adverse Childhood Experiences (ACE) Study' (1998) 14 Am J Prev Med 245.

${ }^{40}$ Stein (n 14).

${ }^{41}$ A Farmer and J Tiefenthaler, 'Explaining the Recent Decline in Domestic Violence' (2003) 21 Contemporary Econ. Pol'y 158.
} 
cancer within the labour market. ${ }^{42}$ In contrast, failing to provide free legal services to disadvantaged groups has both social and economic costs. ${ }^{43}$

Despite the demand for legal advice and the value of its provision, recent public spending policy has reduced the supply of free legal services in England \& Wales. In the austerity measures introduced in 2010 in the wake of the 2008 international financial crisis, the justice system was one of the hardest hit areas of government expenditure, even though many of the incoming public spending cuts directly impacted low income groups most in need of free welfare legal advice. Under pressure to save £2billion from the justice budget by 2014-15, in November 2010 the Ministry of Justice published proposals for the reform of legal aid that would dramatically affect non-criminal legal aid services. ${ }^{44}$ To reduce the public financial deficit, an extensive range of civil and family legal problems, previously within the scope of the legal aid system, were removed at a stroke. ${ }^{45}$

The Legal Aid, Sentencing and Punishment of Offenders Act 2012 (LASPO) came into effect in April 2013. Types of legal problems removed from the scope of legal aid included debt, welfare benefits, employment, education, most housing disputes, private family law (divorce disputes or disputes about children), non-asylum immigration, clinical negligence, consumer or contract disputes, and criminal injury cases. The Act's measures had been passionately opposed and debated throughout its parliamentary passage and the Government was warned of the likely negative impact on vulnerable groups as well as damage to the supply of legal services. The Government's own equality impact assessment accompanying the Act acknowledged that the changes would disproportionately affect women, ethnic minorities and people with disabilities. ${ }^{46}$ Predicted societal impacts included deterioration in case outcomes, wider social and economic costs, and increased resource costs for other Departments.

If the principal aim of LASPO was to cut Ministry of Justice costs, then that objective has certainly been achieved. During the period 2010-2016, MOJ expenditure was reduced by 34 per cent. This was the third largest cut of all Departmental spending, surpassed only by DWP and CLG Local Government. ${ }^{47}$ A recent review of the effects of austerity on the funding devoted to the justice system suggests that 'the UK Government has taken a conscious decision

\footnotetext{
${ }^{42} \mathrm{R}$ Jepson, K Lambe, T Robertson, A Williams, Theory Based Evaluation Of Long Term Conditions and Macmillan Benefit Advice Service in Queen Elizabeth University Hospital, Glasgow (Scottish Collaboration for Public Health Research and Policy, University of Edinburgh 2016) <www.scphrp.ac.uk/wpcontent/uploads/2016/10/evaluation-of-long-term-conditions-macmillan-benefit-service-by-edin-uni.pdf> accessed 2 March 2019.

${ }^{43}$ There is a shortage of robust analyses of the cost of lack of access to justice, but see LK Abel, 'Economic Benefits of Civil Legal Aid' (2012) <https://ncforaj.files.wordpress.com/2012/09/final-economic-benefits-oflegal-aid-9-5-2012.pdf> accessed 26 March 2019. The International Bar Association and World Bank are working on measuring the economic benefits of legal aid. A report is due in October 2019, but the challenges are discussed in a preliminary paper released in October 2018, 'Identifying Economic Benefits of Legal Aid Service Delivery: A Review' <www.ibanet.org/ppid/constituent/accesstojustice_legalaid/default.aspx> accessed 3 March 2019.

${ }^{44}$ Ministry Of Justice, Proposals For Reform Of Legal Aid In England And Wales (Consultation Paper CP12/10, $\mathrm{Cm}$ 7967, 2010) swww.gov.uk/government/publications/proposals-for-reform-of-legal-aid-in-england-andwales $>$ accessed 3 March 2019.

45 ibid para 4.11, P33.

${ }^{46}$ Ministry of Justice, Transforming Legal Aid: Delivering A More Credible and Efficient System, Consultation Paper CP14/2013, Annex K, 5.10.2. For later assessment see Ministry of Justice, Reform of Legal Aid in England and Wales: Royal Assent Stage Equality Impact Assessment (EIA), London (July 2012), P.14, available at: $<w w w . j u s t i c e . g o v . u k / l e g i s l a t i o n /$ bills-and-acts/acts/legal-aid-and-sentencing-act/laspo-background-
} information> accessed 3 March 2019.

47 Institute for Fiscal Studies, Recent Cuts to Public Spending (2015) <www.ifs.org.uk/tools_and_resources/fiscal_facts/public_spending_survey/cuts_to_public_spending > accessed 3 March 2019. 
to substantially withdraw public funding for the support of the justice system and for promoting access to justice'. ${ }^{48}$

In the six years since LASPO was implemented there has been a disturbing change in the provision of free legal advice in both the private and not-for-profit [NFP] sectors at a time when austerity measures have increased the need for legal advice and assistance. ${ }^{49}$ When LASPO was implemented, the MOJ estimated that the changes would lead to a 77 percent loss in legal aid income to NFP legal advice agencies and a 25 percent reduction for legal aid solicitors' firms. This assessment has been broadly accurate and the result has been to push the NFP sector into decline. ${ }^{50} \mathrm{~A}$ recent MOJ survey showed that in the last decade there has been a 50 per cent drop in the number of not for profit (NFP) advice providers, and among those remaining, over half have had to make significant negative changes to their services to survive. ${ }^{51}$

In 2015, in response to mounting concern, a review of the impact of LASPO on access to justice and the provision of legal services was undertaken by the House of Commons Justice Committee. The Committee concluded that there had been a failure to protect access to justice for the most vulnerable. ${ }^{52}$ Although the implementation of LASPO had resulted in significant savings to the MOJ, the capacity for early intervention in legal problems and the opportunity to avert crisis had been lost. One consequence of importance to the current discussion is that 'costs are shifted from the legal aid budget to other public services rather than reduced overall' ${ }^{53}$ A study of the unintended consequences of the legal aid changes argued that while knock on costs would be faced by many Government departments, the worst affected would be the Department of Health which will face increased of the NHS from increased or prolonged adverse impacts'. ${ }^{54}$ The issue of cost shifting leads conveniently to the question of how LASPO has impacted health.

Two post-LASPO research studies provide evidence about how the loss of legal aid for welfare problems is affecting health. A 2018 study commissioned for MIND found that the LASPO scope changes disproportionately affected those with mental health problems. Half of those experiencing legal problems excluded by LASPO had mental health problems. This was far higher than the percentage of those facing problems more generally $(36 \%)$, or the population as a whole $(18 \%) .{ }^{55}$

A very recent study, commissioned by the Equalities and Human Rights Commission, focused on people experiencing family, employment, or welfare benefits problems who would

\footnotetext{
${ }^{48}$ M Chalkley, Funding For Justice 2008 To 2018: Justice In The Age of Austerity; Bar Council, November 2018 <www.barcouncil.org.uk/media/688940/funding for_justice-_the last_10_years_version__professor_martin_chalkley.pdf > accessed 3 March 2019.

${ }^{49}$ Logan Green and Sandbach (n 1); House Of Commons Justice Committee, Impact of Changes to Civil Legal Aid Under Part 1 of The Legal Aid, Sentencing And Punishment Of Offenders Act 2012 (HC 2014-15, 311) <https://publications.parliament.uk/pa/cm201415/cmselect/cmjust/311/311.pdf> accessed 3 March 2019, para 75 .

${ }^{50}$ cf Logan Green and Sandbach (n 1).

51 A Ames, W Dawes and J Hitchcock, Survey of Not For Profit Legal Advice Providers In England And Wales, Ministry of Justice Analytical Series 2015

<https://assets.publishing.service.gov.uk/government/uploads/system/uploads/attachment_data/file/485636/notfor-profit-la-providers-survey.pdf> accessed 3 March 2019. See also The Low Commission, Getting It Right in Social Welfare Law (Legal Action Group 2015) <https://www.lag.org.uk/about-us/policy/the-lowcommission-200551> accessed 3 March 2019, vi.

${ }^{52}$ House of Commons Justice Committee (n 49).

53 ibid 62.

${ }^{54}$ G Cookson, Unintended Consequences: The Cost of The Government's Legal Aid Reforms: A Report for The Law Society of England \& Wales (King's College London 2011) para 5.9.3.

55 Balmer and Pleasence (n 33).
} 
have been eligible for legal aid prior to LASPO. The research found that problems were exacerbated by delays in resolution caused by lack of preventive legal help. Participants experiencing a wide range of social welfare legal problems described stress, anxiety, depression and other emotional or mental and physical health difficulties, including sleeplessness, loss of appetite, and high blood pressure. ${ }^{56}$ The study suggested that LASPO savings on legal aid may ultimately be undercut by expenditure subsequently falling elsewhere, including the cost to the NHS of supporting those whose physical and mental health has deteriorated as a result of health-harming social or welfare problems capable of legal resolution.

\section{Access to Justice in the Post-LASPO World}

In the wake of the legal aid changes, various organizations have turned their minds to the question of how scarce free legal services could be reconfigured to deliver access to justice, particularly for disadvantaged and vulnerable groups. The Low Commission, established in 2012 to develop a strategy for social welfare law advice and support, published several reports between 2013 and 2015. Noting that post-LASPO advice service reductions disproportionately impacted disadvantaged groups, the Commission recommended an approach to provision that focused more on prevention, early advice and the 'smart' location of advice. Specifically, the Commission proposed 'embedding' services in the places that people regularly go, such as GP surgeries and community centres, where people already feel that their needs are being met and where they 'naturally turn' when they need help. ${ }^{57}$

In similar vein, in 2016 Lord Bach's Commission on access to justice in the post- LASPO world described a justice system in crisis with 'hundreds of thousands' of people going without the legal aid that they require. In addition to arguing for 'Right to Justice' legislation, the Commission recommended that remaining face to face social welfare legal services should be taken 'out into their communities', specifically giving the example of provision of welfare legal advice in GPs' surgeries. ${ }^{58}$

As will be discussed in the next section, the idea of integrating community legal services with health services is not particularly novel. But the crisis in access to justice and the need to employ remaining resources more effectively has stimulated some fundamental questioning of traditional patterns of service activity, particularly in the NFP legal sector. The new emphasis in access to justice on service integration, collaboration with non-legal organisations, ${ }^{59}$ on early intervention to avoid crises and on taking a more holistic approach to meet the complex needs of vulnerable individuals and families resonates with developments in public health policy and practice.

\footnotetext{
${ }^{56} \mathrm{~J}$ Organ and J Sigafoos, The Impact Of LASPO On Routes To Justice (2018) Equality and Human Rights Commission, Research Report 118 <www.equalityhumanrights.com/en/publication-download/impact-lasporoutes-justice> accessed 3 March 2019.

${ }^{57}$ Low Commission, Tackling the Advice Deficit: A Strategy for Access to Advice and Legal Support On Social Welfare Law in England And Wales (Legal Action Group 2014) 54; Low Commission, Getting It Right in Social Welfare Law (n 51) 20, 49.

58 Bach Commission, The Right to Justice (Fabian Society 2017) <www.fabians.org.uk/wpcontent/uploads/2017/09/bach-commission_right-to-justice-report-web.pdf> accessed 3 March 2019, 43.

59 There has been significant investment by funders such as the Baring Foundation, the Big Lottery Fund and The Legal Education Foundation to promote systems thinking within the legal advice sector in order to better contribute to improved service delivery. See for example M Smerdon and J Randall, Future Advice, (The Baring Foundation 2013) https://cdn.baringfoundation.org.uk/wp-content/uploads/2014/09/STVSFA8.pdf
} 


\section{Determinants of Health and Health Inequalities}

\section{A. Models of Health and the Importance of Social Determinants}

The organization of healthcare services is strongly influenced by prevailing models of disease, illness and health. Healthcare in the Western world has traditionally been based on a biomedical model of health which focuses on the physical and biological aspects of specific diseases and conditions. Within this framework, health is largely conceptualised as the 'absence of disease' and explanations for disease emphasise physical causes. Health services are organized around the treatment of sick and disabled people and the role of doctors is to investigate, diagnose and treat disease. A high value is placed on the provision of specialist medical services, generally within hospitals or clinics and most healthcare funding is devoted to this approach to improving and maintaining the health of citizens. Medical science and technologies are central in the biomedical model and have led to substantial advances curing disease. ${ }^{60}$

Despite the evident benefits of the biomedical model of health and illness, there has been increasing acknowledgement during the $20^{\text {th }}$ Century that health and wellbeing are affected by a broad range of factors besides individual biology, genetic endowment and access to high quality healthcare services. Social and environmental factors such as income and social status, living conditions, education and literacy, employment and working conditions exert a powerful influence over health and wellbeing. The critical impact of social determinants on health is now well researched and documented. ${ }^{61}$ There is an extensive body of international social epidemiological research establishing that social, economic and environmental factors have a greater impact on individual and population health than individual biology or clinical care. ${ }^{62}$ Estimates put the influence of social and environmental determinants on health status at between $45 \%$ and $60 \%{ }^{63}$

In establishing a Commission on the Social Determinants of Health in 2005, the World Health Organization acknowledged that to achieve an appreciable improvement in public health it was necessary to shift focus from the traditional biomedical model of health, with its concentration on the immediate causes of disease, to a social model that paid more attention to the 'causes of the causes' - in other words the social determinants of health. ${ }^{64}$ As the Health Foundation has recently commented:

The shortcomings of a system that has focused disproportionately on treating disease when it arises, rather than investing in actions that maintain health over the life course, is becoming more visible.... Rather than simply improving society's ability to respond to

\footnotetext{
${ }^{60}$ DT Wade and PW Halligan, 'Do Biomedical Models Of Illness Make For Good Healthcare Systems?' (2004) 329 BMJ 1398.

61 Public Health England, Health Profile For England: 2017 (July 2017) <www.gov.uk/government/publications/health-profile-for-england/chapter-6-social-determinants-of-health> accessed 3 March 2019, ch 6 'Social Determinants of Health'.

${ }^{62}$ M Marmot, Fair Society, Healthy Lives: Strategic Review Of Health Inequalities In England Post 2010, (Institute of Health Equity 2010) <www.instituteofhealthequity.org/resources-reports/fair-society-healthy-livesthe-marmot-review $\geq$ accessed 3 March 2019. See also Improving The Health of The Public By 2040 (Academy of Medical Sciences 2016) <https://acmedsci.ac.uk/file-download/41399-5807581429f81.pdf> accessed 3 March 2019 .

${ }^{63}$ King's Fund, Broader Determinants Of Health <www.kingsfund.org.uk/projects/time-think-differently/trendsbroader-determinants-health > accessed 3 March 2019.

${ }^{64} \mathrm{R}$ Bell, S Taylor and M Marmot, 'Global Health Governance: Commission on Social Determinants of Health and the Imperative for Change’ (2010) 38 JL Med \& Ethics 470, 475.
} 
disease, more emphasis should be placed on actions that promote the conditions for good health. ${ }^{65}$

\section{B. Social Determinants and Health Inequalities}

Although improvements in health and longevity have been considerable since the Second World War, social class and other group difference in health have persisted. The lower a person's socio-economic position, the higher their risk of poor health, referred to as the 'social gradient' ${ }^{66}$ People in each socio-economic category have worse health than those above them in the hierarchy. ${ }^{67}$

Seminal studies of health differences carried out on a cohort of employees in the British Civil Service (the Whitehall Studies) show that differences exist across a range of health outcomes even in people who are employed, live in a wealthy country, and are not suffering absolute material deprivation. Health differences exist across social groups, genders, and ethnicities, between and within countries. While some differences arise from chance genetic factors or because of behaviour, public health policy largely focuses on health differences arising from avoidable differences in social determinants of health such as living and working conditions, education, occupation, income and so on. These are generally termed 'health inequalities' defined as systematic and potentially remediable differences in one or more aspects of health across populations or population groups.

Health inequalities arise as a result of the influence of differently distributed and experienced social determinants of health and well-being. ${ }^{68}$ While the term health difference is merely descriptive, the term health inequality (or sometimes health inequity), ${ }^{69}$ incorporates a moral dimension, and tends to be used when health differences are deemed to be preventable and unnecessary, and therefore 'unjust'. ${ }^{70}$ 'Health equity' is the mission to reduce health inequalities by removing or minimising social obstacles to good health. The focus here is on increasing access to opportunities and conditions that are conducive to good health, particularly for disadvantaged and socially excluded groups.

With universal access to free health services in the UK and improved standards of living over the course of the century there have been overall improvements in many health indicators and mortality rates. Nonetheless, health inequalities remain and have in some cases widened. For example, in England and Wales the life expectancy gap at birth between the top and bottom

\footnotetext{
${ }^{65}$ Healthy Lives for People in the UK: Introducing the Health Foundation's healthy lives strategy, (The Health Foundation 2017) <www.health.org.uk/sites/default/files/healthylivesforpeopleintheuk.pdf > accessed 3 March 2019, 12.

${ }^{66}$ M Marmot and R Wilkinson, 'The Life Course, The Social Gradient and Health' in M Marmot and R Wilkinson (eds), The Social Determinants of Health (OUP 2005).

${ }^{67}$ M Marmot and E Brunner, 'Cohort Profile: The Whitehall II Study' (2005) 34 International Journal of Epidemiology 251.

${ }^{68}$ B Starfield, 'Basic concepts in population health and health care' (2001) 55 J Epidemiol Community Health. 452; see also P Hutt and S Gilmour, Tackling Inequalities In General Practice (King's Fund 2010) <www.kingsfund.org.uk/sites/default/files/field/field_document/health-inequalities-general-practice-gp-inquiryresearch-paper-mar11.pdf > accessed 3 March 2019.

${ }^{69}$ The terms 'health disparities', 'health inequalities' and 'health inequities' are used in the public health literature in often imprecise and conflicting ways. I have adopted the term health inequality to refer to avoidable difference in health between social groups.

${ }^{70}$ M Arcaya, A Arcaya and SV Subramanian, 'Inequalities in Health: Definitions, Concepts, and Theories' (2015) 8 Global Health Action 27106.
} 
social groups was wider in 2007-2011 than in 1982-1986 for both males and females. ${ }^{71}$ The most recent profile of public health in England and Wales concludes that there is no evidence of a narrowing of inequalities in life expectancy in recent years. ${ }^{72}$ People living in the most deprived areas of the country spend nearly a third of their lives in poor health, compared with only about a sixth for those in the least deprived areas. They are more than twice as likely to die prematurely from cancer compared with those in the least deprived areas and almost four times as likely to die prematurely from cardiovascular disease. This inequality in health begins early in life with wide inequalities in child health. ${ }^{73}$

\section{Focusing on the Causes of the Causes}

Despite an abundance of research, the challenge of combatting the impact of disparities in societal resources on health and well-being has become, and remains, a global pre-occupation. There is an extensive body of work that aims to explain the causes of health inequalities, ${ }^{74}$ pointing to the effects of a range of factors including income, socio-economic group, housing conditions, early childhood environment, employment status and educational attainment, as well as psychosocial stress, and health behaviours. ${ }^{75}$ There are many studies assessing bidirectional causal relationships between multiple social determinants and a variety of health outcomes. $^{76}$ The various explanations of how social factors lead to health inequalities involve complex hypothetical pathways arising from differential exposure to health-harming structural factors.

However, there is a dearth of evidence about what interventions are effective at reducing the impact of disadvantageous circumstances on health, or on reducing inequalities in health. Upstream interventions are aimed at diminishing the root causes of illness with high level legislative/policy interventions designed to influence structural determinants of health such as the distribution of wealth, power and opportunities. In contrast, downstream interventions act on the effects of the social/structural causes of illness by focusing on the immediate needs of individuals and families. Interventions may seek to improve access to health, welfare and other services and are often targeted toward groups facing specific adverse health outcomes. While influencing population-wide structural factors is an important longterm target for public health policy, it is necessary to pay attention to the lived experience of

\footnotetext{
${ }^{71}$ Office for National Statistics, Trend in life expectancy at birth and at age 65 by socio-economic position based on the National Statistics Socio-economic Classification, England and Wales: 1982-1986 to 2007-2011 (21 October

<www.ons.gov.uk/peoplepopulationandcommunity/birthsdeathsandmarriages/lifeexpectancies/bulletins/trendinl ifeexpectancyatbirthandatage 65 bysocioeconomicpositionbasedonthenationalstatisticssocioeconomicclassificatio nenglandandwales/2015-10-21\#main-findings> accessed 3 March 2019, pt 1 'Main Findings'.

72 Public Health England, Health Profile for England: 2018 (September 2018) <www.gov.uk/government/publications/health-profile-for-england-2018/ch apter-5-inequalities-in-health> accessed 3 March 2019, ch 5 'Inequalities in Health'.

73 Royal College of Paediatrics and Child Health, State of Child Health Report 2017 (RCPCH 2017) <www.rcpch.ac.uk/sites/default/files/2018-09/soch_2017_uk_web_updated_11.09.18.pdf> accessed 3 March 2019.

${ }^{74}$ For a useful synthesis of work see M Bartley, Health Inequalities (2nd edn, Polity Press 2016); Marmot, Fair Society (n 62).

${ }^{75}$ SA Schroeder, 'We Can Do Better - Improving the Health of The American People' (2007) 357 New England Journal of Medicine 1221, 1225.

${ }^{76}$ For example, H Kröger, E Pakpahan and R Hoffmann, 'What causes health inequality? A systematic review on the relative importance of social causation and health selection' (2015) 25 European Journal of Public Health 951; E Foverskova and A Holm, 'Socioeconomic inequality in health in the British household panel: Tests of the social causation, health selection and the indirect selection hypothesis using dynamic fixed effects panel models' (2016) 150 Social Science \& Medicine 172.
} 
inequality where interventions may help individuals to protect and promote their own health, despite broader social processes outside of their control. ${ }^{77}$

Improved understanding of the causes of the social gradient has led to intensified pressure in research, practice, and policy-making to reduce the gradient through novel interventions. But there are at least two significant problems. First, reviews suggest that the evidence base for social determinants of health is dominated by descriptive, epidemiological studies which highlight associations, but are only implicitly able to suggest possible interventions, when what would be most valuable is evidence of the sort of interventions or innovations that might be effective in improving health or reducing the social gradient. ${ }^{78} \mathrm{~A}$ second perceived weakness in the research on tackling wider determinants of health is the tendency of studies to focus on modifying negative individual health behaviours such as smoking - possibly because these are easier to identify and measure.

There is a pressing need for better understanding about what can be done to alleviate the social determinants of health and health inequalities and, most specifically, which interventions are effective and for whom. A recent evidence synthesis of health and social interventions for socially excluded groups with multiple risk factors such as experience of homelessness, drug use, imprisonment, and sex work identified 'numerous' interventions designed to improve physical and mental health. But, notably, evidence was scarce for interventions aimed directly at social determinants such as housing, employment and legal support that would be very likely to prevent exclusion and promote recovery. ${ }^{79}$ This confirms the impression that the potential of law and legal services to address health inequalities at an individual level and to influence policy at institutional level is not well recognized in public health discussions about how to alleviate health inequalities. Indeed, it has been noted that 'health researchers do not widely share a sense of law as a field of social practice' and that health theory and health research overlook the role of law 'on the streets'. ${ }^{80}$

How then, from a socio-legal perspective, should we attempt to promote health equity? If health inequalities derive predominantly from material, social, and environmental disadvantage, then at least part of the solution may be found in social justice policies that reduce poverty and discrimination, that improve living conditions and lessen the pressure on low income and socially excluded families so that cycles of disadvantage can be broken, and behaviour changed. However, reducing poverty and inequality through policies designed to achieve fundamental structural change is a long-term strategy requiring significant political will. In the short and medium term, ensuring that low income groups benefit from existing protective social entitlements prescribed by law, such as income maintenance, secure employment, healthy housing, appropriate education for children, and security for the vulnerable, has much to commend it. Moreover, the accumulation of legal interventions on behalf of individuals to secure entitlements provides evidence of meso level policy failure and can contribute to the impetus for institutional policy change to address social determinants. Such an approach offers important opportunities for legal and health services to work together to ameliorate health inequalities.

\footnotetext{
${ }^{77}$ J Popay, U Kowarzik, S Mallinson, S Mackian, and J Barker, 'Social Problems, Primary Care and Pathways to Help and Support: Addressing Health Inequalities at the Individual Level. Part I: The GP Perspective' (2007) 61 J Epidemiol Community Health 966.

${ }^{78}$ C Bambra, M Gibson, S Amanda, K Wright, M Whitehead and M Petticrew, 'Tackling the wider social determinants of health and health inequalities: evidence from systematic reviews' (2010) $64 \mathrm{~J}$ Epidemiol Community Health 284. See also K Lucyk and L McLaren, 'Taking Stock of The Social Determinants of Health: A Scoping Review' (2017) 12(5) PLoS ONE e0177306.

${ }^{79} \mathrm{~S}$ Luchenski, 'What Works in Inclusion Health: Overview of Effective Interventions for Marginalised and Excluded Populations' (2018) 391(10117) The Lancet 266.

${ }^{80}$ S Burris, 'From Health Care Law to The Social Determinants of Health: A Public Health Law Research Perspective' (2011) 159 University of Pennsylvania Law Review 1655.
} 


\section{How Can Legal Advice Mitigate Health Inequalities?}

Although disadvantaged citizens and those who care for their health may not recognise the relevance of legal process to the challenging situations that they often face, law can be a powerful tool for improving the lives of the poor and vulnerable ensuring that they have access to critical protections and entitlements prescribed by law. The provision of free legal advice has long been understood, within the legal sector at least, to have value for the health and wellbeing of low income and vulnerable groups where legal support can make the difference between 'stable housing, predictable cash flow, custody of one's children, employment and access to credit on the one hand, and bad credit, uncertain housing, family separation, unemployment or bankruptcy on the other' ${ }^{81}$ In cases such as asthma caused by poor social housing, legal services have the power to improve health when medical services alone cannot. In the quest to transform the design of health and associated services to reduce health inequalities, collaboration between lawyers and healthcare providers presents one constructive approach.

The most powerful lever at our disposal to fix and redesign these determinants of health is the law, and medical legal partnership is one example of an intervention that can squarely address both upstream factors and downstream, in the moment patient needs. ${ }^{82}$

How does this work in practice? What is the theory of change that would help us to understand the role of legal advice and support in improving health and well-being and mitigating social determinants of health? How do we establish direct causal links between advice and improved health and wellbeing or service use?

One suggested approach, based on a systematic review of the literature, ${ }^{83}$ has mapped a series of causal pathways between the direct outcomes of advice, such as improved housing or increased benefit income, and intermediate impacts, such as reduced anxiety and stress to longer term improvements in mental and physical health. Subsequent research to test the model has found that advice can lead to immediate improvements in finances or living conditions which relieves acutely stressful experiences that may precipitate or exacerbate physical or mental health problems ${ }^{84}$ Put simply, legal practitioners have the knowledge, training and skills to address legal needs that arise from a subset of health harming social pathogens. To illustrate, Figure 1 suggests the different approaches and outcomes to example medical conditions of the traditional biomedical model as compared with a service model that integrates legal advice and support.

\footnotetext{
${ }^{81}$ Sandefur (n 17) 457, also citing L Abel and S Vignola, 'Economic and other benefits associated with the provision of civil legal aid' (2010) 9 Seattle J Soc Just 139, 145, reviewing evidence of the impact of legal assistance to people facing challenges to the ability to meet basic human needs.

82 Teitelbaum and Lawton (n 8) 377.

${ }^{83}$ P Allmark, S Baxter, E Goyder, L Guillaume, and G Crofton-Martin, 'Assessing the Health Benefits of Advice Services: Using Research Evidence and Logic Model Methods to Explore Complex Pathways’ (2013) 21 Health Soc Care Community 59.

${ }^{84}$ N Forster, S M Dalkin, M Lhussier, P Hodgson and S M Carr, 'Exposing the Impact of Citizens Advice Bureau Services on Health: A Realist Evaluation Protocol' (2016) 6(1) BMJ Open e009887.
} 
Figure 1.85

\begin{tabular}{|cl|}
\hline \multicolumn{2}{|c|}{ Biomedical model } \\
\hline Medical condition & \multicolumn{1}{c|}{ Medical intervention } \\
\hline Chronic asthma & $\begin{array}{l}\text { Increase asthma medication } \\
\text { dose and frequency, refer to } \\
\text { specialist clinic }\end{array}$ \\
\hline \multirow{2}{*}{ Insomnia in pregnant woman } & $\begin{array}{l}\text { Sleep hygiene advice, hypnotic } \\
\text { medications, referral to } \\
\text { psychological therapies }\end{array}$ \\
\hline Suicidal ideation or deliberate self- \\
harm & $\begin{array}{l}\text { Mental health referral, } \\
\text { safeguarding, emergency } \\
\text { assessment, psychotropic } \\
\text { medications }\end{array}$ \\
\hline Lower back pain & $\begin{array}{l}\text { Analgesia, imaging } \\
\text { investigations, surgical referral }\end{array}$ \\
\hline \multirow{2}{*}{ Malnutrition, anaemia, iron deficiency } & $\begin{array}{l}\text { Supplemental nutrition } \\
\text { milkshakes, iron supplements, } \\
\text { Vitamin B12 and folate }\end{array}$ \\
\hline
\end{tabular}

Integrating upstream causes, social pathogens and using legal interventions to achieve long term solutions

\begin{tabular}{|c|c|c|c|}
\hline Social Pathogen & Medical condition & Medical intervention & Legal remedy \\
\hline $\begin{array}{l}\text { Poor quality damp } \\
\text { housing }\end{array}$ & Chronic asthma & $\begin{array}{l}\text { Increase asthma } \\
\text { medication dose and } \\
\text { frequency, refer to } \\
\text { specialist clinic }\end{array}$ & $\begin{array}{l}\text { Compel landlord to } \\
\text { comply with legal duty to } \\
\text { provide healthy safe } \\
\text { housing. Check income } \\
\text { entitlements. Increase } \\
\text { income to enable move } \\
\text { to better accommodation }\end{array}$ \\
\hline $\begin{array}{l}\text { Employer illegally } \\
\text { threatening with } \\
\text { redundancy }\end{array}$ & $\begin{array}{l}\text { Insomnia in pregnant } \\
\text { woman }\end{array}$ & $\begin{array}{l}\text { Sleep hygiene advice, } \\
\text { hypnotic medications, } \\
\text { referral to psychological } \\
\text { therapies }\end{array}$ & $\begin{array}{l}\text { Compel employer to } \\
\text { comply with legal duty to } \\
\text { protect employment of } \\
\text { pregnant employees }\end{array}$ \\
\hline $\begin{array}{c}\text { Landlord threatening } \\
\text { eviction }\end{array}$ & $\begin{array}{l}\text { Suicidal ideation or } \\
\text { deliberate self-harm }\end{array}$ & $\begin{array}{l}\text { Mental health referral, } \\
\text { safeguarding, emergency } \\
\text { assessment, } \\
\text { psychotropic medications }\end{array}$ & $\begin{array}{l}\text { Prevent eviction and or } \\
\text { compel local authority to } \\
\text { provide housing } \\
\text { assistance }\end{array}$ \\
\hline $\begin{array}{l}\text { Unsafe working } \\
\text { conditions }\end{array}$ & Lower back pain & $\begin{array}{l}\text { Analgesia, imaging } \\
\text { investigations, surgical } \\
\text { referral }\end{array}$ & $\begin{array}{l}\text { Compel employer to } \\
\text { modify working } \\
\text { conditions or provide } \\
\text { reasonable adjustments } \\
\text { to accommodate }\end{array}$ \\
\hline $\begin{array}{l}\text { Insufficient income for } \\
\text { healthy diet }\end{array}$ & $\begin{array}{l}\text { Malnutrition, anaemia, } \\
\text { iron deficiency }\end{array}$ & $\begin{array}{l}\text { Supplemental nutrition } \\
\text { milkshakes, iron } \\
\text { supplements, Vitamin } \\
\text { B12 and folate }\end{array}$ & $\begin{array}{l}\text { Check income } \\
\text { entitlements. Increase } \\
\text { income by applying for } \\
\text { unclaimed benefit. } \\
\text { Appeal decision to deny } \\
\text { or withdraw benefits. }\end{array}$ \\
\hline
\end{tabular}

${ }^{85}$ I am grateful to Dr M Appleby for his assistance with this diagram. 


\section{Tackling Health Inequalities Through New Service Models}

\section{A. Collaboration, integration and social prescribing}

Almost a decade on from Michael Marmot's 2010 seminal report on social determinants of health, health inequalities seem to be widening and progress on increased life expectancy appears to have stalled. It is now routinely argued and accepted that to improve the health of the public, reduce health inequalities and relieve the crisis in primary care, something more is needed than merely increasing expenditure on treating disease. A strategic approach to better public health and well-being involves addressing the systemic multi-level social causes of health problems and health inequalities, such as low income, poor housing, employment situation and educational opportunities. ${ }^{86}$ But what should that strategy involve? An important trend is for service integration.

For at least two decades, the NHS has been urged to make better use of non-clinical interventions, such as drawing on the services of voluntary organizations, to help mitigate some of the social determinants of health and relieve pressure on GP practices. ${ }^{87}$ In 2006 the Department of Health advocated a 'fundamental shift' towards integrated services provided in local communities and the introduction of 'information prescriptions' for patients with longterm conditions. ${ }^{88}$. Since then the use of 'social prescriptions' has increased in general practices around the country, providing hard pressed GPs with non-medical referral options to improve the health and well-being of their patients. ${ }^{89}$ In 2016, NHS England appointed a GP as a national clinical champion for 'social prescribing' to promote access to non-clinical interventions. It is fair to say that the social prescribing 'movement' in primary care has developed considerable traction and schemes across the country now link patients with a wide range of services and activities such as volunteering, arts activities, group learning, gardening, befriending, cookery, healthy eating, and a range of sports activities. ${ }^{90}$ While 'advice' appears in the list of services included under the social prescribing umbrella, the value of social welfare legal services has not been at the forefront of much social prescribing thinking or debate, despite the fact that in a hierarchy of need, it is arguable that services to secure adequate income, housing, employment, and personal security should be prioritised.

The greater emphasis on collaboration has been recognised in legislation in the Health and Social Care Act 2012 which places legal duties on NHS England to 'have regard to the need to reduce inequalities' between patients in access to, and outcomes from, healthcare services and in ensuring that services are delivered in an integrated way. Having regard means that health inequalities must be considered properly and seriously during decision-making processes or exercising functions. As part of the implementation of the Health and Social Care Act upper tier local authorities now have responsibility for improving the health of their local communities working in partnership with Clinical Commissioning Groups (CCGs) and others

\footnotetext{
${ }^{86}$ Public Health England (n 61); Marmot, Fair Society (n 62); Improving The Health of The Public By 2040 (n $62)$.

${ }^{87}$ Department of Health, Saving Lives: Our Healthier Nation (Cm4386, 1999).

${ }^{88}$ Department of Health, White Paper. Our Health, Our Care, Our Say: A New Direction For Community Services (Cm6737,

<https://assets.publishing.service.gov.uk/government/uploads/system/uploads/attachment_data/file/272238/673 7.pdf> accessed 3 March 2019.

${ }^{89}$ For a helpful description of the history and scope of social prescribing see King's Fund What is Social Prescribing (2017) <www.kingsfund.org.uk/publications/social-prescribing\#what-is-it> accessed 3 March 2019.

${ }^{90}$ MJ Polley, J Fleming, T Anfilogoff and A Carepenter, Making Sense of Social Prescribing (University of Westminster 2017) <http://westminsterresearch.wmin.ac.uk/19629/1/making-sense-of-socialprescribing\%202017.pdf > accessed 3 March 2019.
} 
through health and wellbeing boards. Early intervention and prevention are important objectives and local authorities are required to integrate advice and information services within their health and wellbeing strategies.

A new report by the Institute for Health Equity argues that healthcare services must integrate with other sectors to form 'place-based health systems that influence wider community, social and economic drivers of health'. ${ }^{91}$ This approach again urges services to concentrate on prevention and stresses the need for cross-sector collaboration reaching beyond health and social care to reduce health inequalities. But what ought to be the role of legal services in this policy push for collaboration and integration to address social determinants of health and reduce health inequalities?

\section{B. Integrating Legal and Health Services - Health Justice Partnership}

So powerful is the intuitive logic of social welfare lawyers working hand in hand with healthcare professionals for the benefit of disadvantaged groups that an enthusiastic grass roots service innovation has been developing in the UK, USA and Australia over the past two decades. Known as 'Medical Legal Partnership' (MLP) in the USA, and 'Health Justice Partnership' (HJP) in Australia, in the UK social welfare legal services have been working in partnership with healthcare providers through different models since the early1990s. Health justice partnership broadly describes collaboration between legal and health professionals in which access to free legal support is provided in health settings to disadvantaged and vulnerable patients to address legal needs that can create and exacerbate mental and physical health problems. Or viewed from the health perspective, health justice partnership addresses health harming social determinants that have a legal component. Medical-Legal Partnership has been described as:

An approach to health that integrates the expertise of healthcare, public health and legal professionals and staff to address and prevent health-harming social and legal needs for patients, clinics and populations. By partnering together, healthcare, public health and legal institutions transform the healthcare system's response to social determinants of health. ${ }^{92}$

This description has been recognized by Health Justice Australia as capturing the essence of health justice partnership and it applies equally to the development of integrated health and social welfare legal services in the UK. Health Justice Australia has added an elaboration specifying the groups that health justice partnerships seek to serve:

Health justice partnerships embed legal help into healthcare services and teams to improve health and wellbeing for: individuals, through direct service provision in places that they access; people and communities vulnerable to complex need, by supporting integrated service responses and redesigning service systems around client needs and

\footnotetext{
${ }^{91}$ J Allen, P Goldblatt, S Daly, J Jabbal and M Marmot, Reducing Health Inequalities Through New Models of Care (Institute of Health Equity 2018) <www.instituteofhealthequity.org/resources-reports/reducing-healthinequalities-through-new-models-of-care-a-resource-for-new-care-models> accessed 3 March 2019.

${ }^{92}$ National Center for Medical-Legal Partnership, The Medical-Legal Partnership Toolkit: Phase I: Laying the Groundwork \& Phase II: Building Infrastructure, The Medical-Legal Partnership Toolkit, (Milken Institute School of Public Health at the George Washington University 2015) 2.
} 
capability; vulnerable populations through advocacy for systemic change to policies which affect the social determinants of health. ${ }^{93}$

Health justice partnership provides a range of services to patients addressing simple as well as more complex legal issues. The vision of HJP is to provide accessible free legal advice that can remedy existing legal problems affecting health, avoid escalation of problems that might lead to health issues, and work to prevent ill health from leading to socio-legal problems, for example in the case of cancer or dementia including legal services as part of the 'care pathway' following diagnosis. ${ }^{94}$

Health justice partnership builds on citizens' trust in healthcare providers to deliver street level legal advice services that secure the entitlements and benefits needed by low income and vulnerable patients (such as income maintenance, appropriate housing, employment security, special education, family security) and, in so doing, improve health and well-being.

There are many different models of health justice collaboration ranging from lawyers embedded within the healthcare team in primary or acute settings to co-location or looser referral arrangements. Whatever the model, the drive to integrate health and legal services has come from a practitioner-led understanding of how partnership can address unmet health harming legal need and contributes to holistic support of patients whose medical conditions have an underlying legal dimension, such as unhealthy living conditions or stress arising from loss of employment. In many cases, partnership activities go beyond the provision of legal assistance to patients and extend to involve cross-disciplinary training, care coordination and systemic advocacy. ${ }^{95}$

What is the advantage of locating legal services in health settings? While there are examples of social welfare legal services situated in a variety of settings - such as community or faith centres and food banks - the benefit of integration with health services is the range of people served and the opportunity to build on the trust that they have in their health professionals. Evidence suggests that co-location of advice services increases access for those otherwise potentially unable or unwilling to seek advice (such as older and disabled people) and reduces stigma associated with advice receipt. ${ }^{96}$ In some cases people simply seek help from the service or worker who they are in contact with when a crisis hits or a problem arises. ${ }^{97}$ GP surgeries are accessible and trusted, so health justice partnership can build on that foundation to reach people who would not otherwise seek legal advice and support. Taking a holistic approach to mitigating the effects of negative social determinants of health, health

\footnotetext{
${ }^{93}$ S Forell and T Boyd-Caine, Service models on the health justice landscape: a closer look at partnership, Discussion Paper, Health Justice Australia, October 2018, p 11. https://www.healthjustice.org.au/wpcontent/uploads/2018/12/Health-Justice-Australia-Service-models-on-the-health-justice-landscape.pdf

${ }_{94}$ Jepson and others (n 42).

95 S Forell, Mapping a New Path: The Health Justice Landscape in Australia 2017, Health Justice Australia, (2018) <www.healthjustice.org.au/wp-content/uploads/2018/08/Health-Justice-Australia-Mapping-a-newpath.pdf> accessed 3 March 2019; see also M Regenstein, J Trott, A Williamson, and J Theiss, 'Addressing Social Determinants of Health Through Medical-Legal Partnerships' (2018) 37(3) Health Affairs 378; Advancing Health Equity.

96 J Burrows, S Baxter, W Baird, J Hirst, and E Goyder, 'Citizens Advice in Primary Care: A Qualitative Study of The Views and Experiences of Service Users and Staff' (2011) 125(10) Public Health 704; T Haigh, Tower Hamlets Health \& Advice Links Project (Social Action For Health 2012); P Greasley and N Small, 'Providing Welfare Advice in General Practice: Referrals, Issues and Outcomes' (2005) 13(3) Health and Social Care in the Community 249.

${ }^{97}$ S Clarke and S Forell, 'Pathways To Justice: The Role Of Non-Legal Services' (2007) Law And Justice

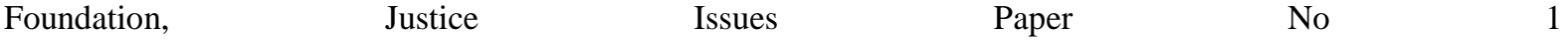
<www.lawfoundation.net.au/ljf/site/articleids/b0b818584c14f361ca257306000716a2/\$file/pathways_to_justice. pdf $\geq$ accessed 3 March 2019, 4.
} 
justice partnership is the vehicle through which social welfare law becomes part and parcel of the approach to improving the health of citizens.

From a health services perspective, integrating lawyers in health settings supports health professionals. GPs are routinely dealing with a wide variety of social as well as medical issues ${ }^{98}$ and patient demand for such 'non-health' work is contributing to increased general practice pressures. ${ }^{99}$ Patient health, GP workload and practice staff time have been adversely affected by greater patient financial hardship and changes to welfare provision, negatively impacting services and increasing job stress. ${ }^{100}$ Health justice partnership has the potential to assist GPs in providing a more effective service for patients with complex needs and so contribute to easing some of the growing service pressures.

\section{The Development of Health and Legal Services Partnership in the UK}

The potential benefit of co-locating health and legal services has been recognised in the UK for at least three decades. In 1985, the BMJ carried an article by a GP advocating the provision of welfare benefits advice within GP surgeries to achieve improvements in health and reduce costs to the state. Noting that the surgery's heavy users included a high proportion of patients not receiving welfare benefits to which they were entitled, Jarman argued that although GPs could detect patients whose health was suffering because of financial hardship, they were illequipped to give benefits advice, which ought to be provided by professional advisers located within the practice. ${ }^{101}$

In 1990, to address the impact of poverty on health and consequent demand for health services, South Birmingham Health Authority funded an innovative programme in which Citizens Advice Bureaux [CABx] provided social welfare legal advice and counselling within general practices. An evaluation of the scheme concluded that $\mathrm{CABx}$ located in general practices reached a different group of clients from those who used mainstream CAB outlets, that these clients (patients) were more likely to be ill, and that they were also more likely to be failing to receive welfare benefits to which they were entitled. ${ }^{102}$

In 1998 the Acheson Inquiry on health inequalities ${ }^{103}$ recommended increasing the uptake of welfare benefits among entitled groups by establishing a 'welfare counsellor' in primary care centres in disadvantaged areas. ${ }^{104}$ In the following year, health authorities committed some $£ 2$ million to fund social welfare legal advice provided by CABs within health settings. ${ }^{105}$ Local authorities also provided funding to provide welfare advice for patients in

\footnotetext{
${ }^{98}$ J Popay, U Kowarzik, S Mallinson, S Mackian and J Barker,'Social Problems, Primary Care and Pathways to Help and Support: Addressing Health Inequalities at The Individual Level. Part I: The GP Perspective’ (2007) 61(11) Journal of Epidemiology and Community Health 966.

${ }^{99}$ B Baird, A Charles, M Honeyman, D Maguire and P Das, Understanding Pressures in General Practice. (The King's Fund, May 2016) <www.kingsfund.org.uk/sites/default/files/field/field_publication_file/UnderstandingGP-pressures-Kings-Fund-May-2016.pdf> accessed 2 March 2019; G Iacobucci, 'GPs' Workload Climbs as Government Austerity Agenda Bites' (2014) 349 BMJ g4300.

${ }^{100}$ Citizens Advice, A Very General Practice: How Much Time Do GPs Spend on Issues Other Than Health? (2015)

<www.citizensadvice.org.uk/Global/CitizensAdvice/Public\%20services\%20publications/CitizensAdvice_AVer yGeneralPractice_May2015.pdf> accessed 3 March 2019.

${ }^{101}$ B Jarman, 'Giving Advice About Welfare Benefits in General Practice' (1985) 290 BMJ 522.

102 JA Paris and D Player, 'Citizens' Advice in General Practice' (1993) 306 BMJ 1518.

$103 \mathrm{D}$ Acheson, Independent Inquiry into Inequalities in Health (The Stationery Office 1998). <https://assets.publishing.service.gov.uk/government/uploads/system/uploads/attachment_data/file/265503/ih.p df> accessed 3 March 2019.

104 ibid recommendation 3.3.

105 Greasley and Small (n 96).
} 
primary care settings. At the time, the typical model was for an advice worker to be located within a GP surgery on a sessional basis with referrals being made by GPs, other health care staff, or via self-referral.

Since these developments in the early 1990s, there has been a steady growth of health justice projects across England, Wales and Scotland supported by legal aid, local authority, health and charity funding. The potential of HJP was spotted by the Low Commission and a key strand in their review of post-LASPO legal advice provision focused on the relationship between social welfare legal advice needs and health outcomes. To assist this work, they commissioned a rapid study of the state of the field and a review of existing evidence on the benefits of HJP. In 2015, their report identified 58 examples of advice services working in a range of health settings. ${ }^{106}$

In 2016, building on legal needs research, the UCL Centre for Access to Justice (CAJ) established its own health justice partnership. Co-located with a general practice in a deprived area of East London, the UCL Integrated Legal Advice Clinic (iLAC) provides free legal advice on social welfare law to patients referred by the practice, as well as patients referred from other practices and those who self-refer. Since 2016, iLAC has provided social welfare legal support to local residents and carried out research on the health and well-being effects of the service. ${ }^{107}$

Developing out of this health justice work, in 2018 CAJ completed a comprehensive mapping exercise of HJP activity in England \& Wales, which identified some 383 advice services working within or in connection with healthcare settings. ${ }^{108}$ While this demonstrates that health justice partnership is widespread and more extensive than that found by the Low Commission in 2015, it may still be an underestimate. ${ }^{109}$

Current health justice collaboration models range from fully integrated legal and health services working as a team, to co-located services or direct referral arrangements. Where services are part of a GP social prescribing arrangement, referrals to legal services are generally made by the practice 'link worker'. About two thirds of advice services are physically located within a health setting such as GP practices, mental health services, hospitals and various community health services; others work with hospices, care homes, and social care services. Some health justice partnerships cater for specific conditions such as cancer or HIV, and others target certain patient groups such as the elderly, those with mental health conditions, frequent practice attenders, or victims of domestic violence.

While a wide range of social welfare legal support providers are involved in HJP, including charities, local authorities, and independent organizations, Citizens Advice and Macmillan Cancer Care Support dominate provision, delivering about two-thirds of identified services.

Problems with welfare benefits, debt, housing, employment, health and community care are the most common matters dealt with by health justice partnerships, although assistance

\footnotetext{
${ }^{106}$ A Parkinson and J Buttrick, The Role of Advice Services in Health Outcomes: Evidence Review and Mapping Study (Consilium Research and Consultancy 2015) 57.

107 The research is funded by The Legal Education and the results will be published in 2019.

${ }^{108}$ S Beardon and H Genn, The Health Justice Landscape In England And Wales: Mapping Social Welfare Advice In Health Settings (UCL Centre For Access to Justice and The Legal Education Foundation 2018) <www.ucl.ac.uk/access-to-justice/sites/access-to-justice/files/lef030_mapping_report_web.pdf> accessed 3 March 2019.

${ }^{109}$ For example, in June 2018 Citizens Advice reported that they provide 'outreach' support in over 500 GP surgeries and other health locations across England \& Wales, although some of this may be limited to information provision only. See Citizens Advice and Royal College of General Practitioners, Advice In Practice: Understanding The Effects of Integrating Advice in Primary Care Settings, (2018) $<$ www.citizensadvice.org.uk/global/public/impact/understanding\%20the\%20effects\%20of\%20advice\%20in\%20 primary\%20care\%20settings_research\%20report\%20(final).pdf $>$ accessed 3 March 2019.
} 
is also being given for end-of-life issues, equalities and care act, injunctions, energy and education. Services are delivered via face-to-face appointments, telephone and email, providing information, advice, form-filling, and casework that incorporates advocacy and tribunal representation where required. Some services also offer training for healthcare staff to help them identify and support patients with welfare issues.

The UCL mapping study highlights the fragility of funding for co-located welfare legal support services. The development of HJP in England to date has been dependant on regional, local government or charitable funding, and much of it has been very short term. Two thirds of the services identified in the UCL mapping study had funding for three years or less and more than a third had funding for no more than a year. Unsurprisingly, while there are examples of health justice partnerships of considerable longevity, ${ }^{110}$ others have come and gone.

Elsewhere in the UK there are regional government HJP initiatives. In Wales, the Government has, since 2001, funded a programme of welfare advice services in GP surgeries and other health settings known as 'Better Advice, Better Health' [BABH] to increase benefit take-up as a route to better health. A 2015 service evaluation concluded that BABH was reaching individuals who would otherwise have been unlikely to access the advice they needed and that providing support to access unclaimed benefits reduced levels of stress and anxiety among patients using the service. ${ }^{111}$ In Scotland, funding has been made available to 'embed' welfare rights advisers within general practice. Currently over 50 practices have this arrangement, mainly in areas of significant deprivation. The purpose is to better support patients with complex needs via integration of community legal services with primary care. The funding of these services again varies geographically, sometimes supported by local authorities, by NHS board funding or Scottish Government funding. ${ }^{12}$

The development of health justice partnership in the UK context has been driven by a strong experiential belief among both health professionals and legal service providers in the value of the model for disadvantaged and vulnerable patients. The HJP movement has largely proceeded in advance of a robust evidence base for the value of intervention, essentially on a foundation of intuitive logic or 'face validity'. ${ }^{113}$ However, over the past decade there has been mounting interest among health and legal researchers in evaluating the benefit of integrated health and legal services.

\section{Research on Health Justice Partnership}

There is now a modest body of UK and international health justice research empirically investigating the operation and outcomes of integrated health and legal services. The focus of most of the studies has been on exploring the financial, health and well-being benefits for patients. Some attention has been paid to the value of integrated services for doctors and

\footnotetext{
${ }^{110}$ For example, Bromley by Bow Centre <www.bbbc.org.uk/services/specialist-advice > accessed 3 March 2019.

${ }^{111}$ Arad Research, An Assessment of The Implementation of the 'Better Advice, Better Lives' Scheme: Final Report (2015) Welsh Government Social Research 66/2015 <https://gov.wales/sites/default/files/statistics-andresearch/2018-12/151125-assessment-implementation-better-advice-better-lives-scheme-en.pdf $>$ accessed 27 March 2019.

$112 \mathrm{~J}$ Sinclair, The Deep End Advice Worker Project: Embedding an Advice Worker in General Practice Settings (Glasgow Centre For Population Health, September 2017) <https://www.gcph.co.uk/assets/0000/6242/Deep_End FINAL WEB.pdf $>$ accessed 3 March 2019.

113 'Face validity' is a term used in research for something that 'looks like it will work' rather than having been proven to work. I am indebted to Ellen Lawton CEO of National Center for Medical Legal Partnership for her use of the term in conversation about HJP.
} 
practice staff, and on service demand, as well as the practicalities, professional and ethical challenges involved in integrating health and legal services.

Looking at outcomes, systematic literature reviews of HJP studies have found that financial gains to patients receiving legal assistance substantially outweigh the costs of providing services ${ }^{114}$ and that there is a range of other beneficial outcomes to health, well-being and social functioning. ${ }^{115}$ Legal assistance provided through HJP has been associated with reduced stress and anxiety among service users; improved confidence; better sleeping patterns; reversal of unintended weight loss; increased social participation; changes in medication; smoking reduction or cessation; improved diet and physical activity. ${ }^{116} \mathrm{~A}$ recent controlled quasi-experimental study of a HJP in a general practice found that most service users reported improvements in circumstances, particularly in stress, income, housing circumstances and confidence. ${ }^{117}$

There is also evidence that HJP has the potential to reduce general practice workload pressures, and GP consultations. ${ }^{118}$ GPs spend about $80 \%$ of their time on $20 \%$ of their patients. ${ }^{119}$ Systematic reviews show that physical and psychiatric illness, emotional distress, social problems, medically unexplained symptoms, health anxiety and poor perceptions of health are all significant predictors of 'frequent attendance'. ${ }^{120}$ Integrated legal assistance which might reduce psychosocial stressors on patients, such as threatened eviction or domestic abuse, might have the potential to impact consultation rates. Integrated legal services can address underlying social issues that affect health but cannot be alleviated by medical intervention. They can provide practices with a referral option for staff who lack the time and appropriate expertise to assist patients with socio-legal problems and reduce GP time spent on health-related benefit form filling, housing letters, and so on. While there is some evidence from qualitative research that HJP leads to a reduction in contact with health services, so far there is no rigorous assessment of the health service impact of health justice partnership. ${ }^{121}$

\footnotetext{
${ }^{114}$ J Adams, M White, S Moffatt, D Howel and J Mackintosh, 'A Systematic Review of The Health, Social and Financial Impacts of Welfare Rights Advice Delivered in Healthcare Settings' (2006) 6 BMC Public Health 81. ${ }^{115}$ M Farr, P Cressey, SE Milner, N Abercrombie and B Jaynes, Proving the Value of Advice: A Study of The Advice Service of Bath and North East Somerset Citizens Advice (South West Forum 2014).

${ }^{116}$ Allmark and others (n 83); Parkinson and Buttrick (n 106).

${ }^{117}$ C Woodhead, M Khondoker, R Lomas and R Raine, 'Impact of Co-Located Welfare Advice in Healthcare Settings: Prospective Quasi-Experimental Controlled Study’ (2017) 211(6) Br J Psychiatry 388.

${ }^{118}$ C Woodhead, H Collins, R Lomas and R Raine, 'Co - Located Welfare Advice in General Practice: A Realist Qualitative Study' (2017) 25 Health and Social Care in The Community 1794.

${ }^{119}$ RD Neal, PL Heywood, S Morley, AD Clayden and AC Dowell, 'Frequency of Patients' Consulting in General Practice and Workload Generated by Frequent Attenders: Comparisons Between Practices’ (1998) 48(426) 895 British Journal of General Practice 895.

${ }^{120}$ FTM Smits, HJ Brouwer, G ter Riet and HCP van Weert, 'Epidemiology of Frequent Attenders: A 3-Year Historic Cohort Study Comparing Attendance, Morbidity and Prescriptions of One-Year and Persistent Frequent Attenders' (2009) 9 BMC Public Health 36.

${ }^{121}$ Parkinson and Buttrick (n 106).
} 
Research on the practicalities of integrating health and legal services points to the challenges of partnership working and the critical need to secure buy-in from health professionals. Necessary factors are proactive promotion of services by funders, central government, health organisations and professional membership bodies ${ }^{122}$ as well as active engagement and promotion by practice managers. Other challenges include size of the practice and staff turnover; some clinicians lack of belief that they have a role to play in supporting patients with legal needs; insufficient training in how to address socio-legal issues; lack of understanding about how welfare law services can help patients (and clinicians or other practice staff), and lack of feedback about outcomes of advice. ${ }^{123}$

Published US studies on Medical-Legal Partnership have reported reductions in patient stress; improvements in asthma control; better use of preventive care for new-borns and infants; decreases in readmission rates, inpatient stays, and emergency department visits. Clinicians involved in MLP have reported greater confidence in their ability to initiate discussions about legal issues and better understanding of the impact of social conditions on health. ${ }^{124}$

Notwithstanding these positive research findings, a US literature review in 2013 concluded that much of the existing research 'focuses on describing partnership, with very few articles providing systematically derived evidence of the benefit of MLP services'. ${ }^{125}$ Similarly, the Low Commission review of existing research on advice and health outcomes in the UK, USA, Australia concluded that there was a shortage of studies involving robust outcome measures and long-term follow up of clients. ${ }^{126}$

Despite the potential for research on the role of law in addressing and alleviating social determinants of health at the individual, institutional and societal levels, and despite the relative longevity of the innovative HJP/MLP models, the evidence base needs strengthening in terms of understanding the most effective models of partnership and integration, and the impact of integrated services on a wide range of outcomes. Robust outcomes-based research could support the development of HJP and improve understanding of how accessing social welfare and familial rights and entitlements can mitigate health inequality. The extant health justice studies often have small sample sizes, inconsistent measurement tools and outcomes, insufficient follow up, and lack of a control or comparison to assess the counterfactual. There is also rather weak attention to how integrated services produce change, which groups are most likely to benefit, which models are most effective and the factors influencing implementation and outcomes.

The socio-legal problems that create and exacerbate ill-health require rigorous investigation and the 'black box' of legal assistance as an intervention needs to be opened-up to best explain the pathways linking it with health inequalities. There is a need for greater empirical testing of theories around the specific mechanisms through which outcomes from legal assistance may lead to health and health service improvements. The opportunities for advancing health justice research are discussed in the next part.

\footnotetext{
122 ibid 58.

${ }^{123}$ Woodhead and others (n 118).

${ }^{124} \mathrm{~T}$ Beeson, B McAllister and M Regenstein, Making the Case for Medical-Legal Partnerships: A Review of The Evidence (National Center for Medical-Legal Partnership 2013). <http://medical-legalpartnership.org/wpcontent/uploads/2014/03/medical-legal-partnership-literature-review-february-2013.pdf > accessed 3 March 2019.

125 ibid 6.

${ }^{126}$ Parkinson and Buttrick (n 106) 57.
} 


\section{The Emerging Transdisciplinary Field of 'Health Justice'}

\section{A. Describing the Field}

Although it is in the early stages of evolution, it seems worthwhile to attempt to describe, if not define, the transdisciplinary field of health justice, the boundaries of which remain fluid and within which there is international variation in focus resulting from diversity in the extent to which social, economic, political and structural factors influence health inequalities. For example, in the USA unequal access to healthcare is of greater significance in the quest for health equity than in the UK which has universal free access to healthcare.

In their recent book entitled Health Justice, Tobin-Tyler and Teitelbaum describe the concept of 'health justice' rather inclusively, as, '[L]aws, policies, systems and behaviors that are evenhanded with regard to and display genuine respect for everyone's health and wellbeing - essentially pretty much anything and everything to do with the ambition of health equity'. ${ }^{127}$

I have already argued that the practice of health justice partnership is a grass roots movement founded on the intuitive logic and experience of health and community legal practitioners. The transdisciplinary field of health justice is one of theory, research, practice innovation, education and training, and systemic advocacy. It is concerned with the role of law both as a determinant of health and as a means of mitigating health inequalities. The field of health justice has emerged from socio-legal and social-epidemiological theory and research insights that highlight the interconnections between health inequalities and access to legal services. A central question is how joining together legal and health services can transform provision for disadvantaged and vulnerable groups to improve wellbeing and alleviate health inequalities.

The health justice field can be differentiated from public health law with its attention on population-level legislative intervention such as alcohol pricing, water fluoridisation, environmental regulation and so on. ${ }^{128}$ It can also be distinguished from the macro level concerns of legal epidemiology defined as 'the scientific study and deployment of law as a factor in the cause, distribution, and prevention of disease and injury in a population' ${ }^{129}$ Health justice, in contrast, has a specific and perhaps narrower focus on improving the health and wellbeing of disadvantaged and vulnerable groups, and emphasises the value of interventions at the micro and meso level that work to enforce existing legal protections and social justice policies. This is because the ability of individuals to access legal protection is not merely a matter of law and policy 'on the books', but also of implementation. This field explores how health, legal and other professionals working in partnership may contribute to more effective enforcement of laws and regulations that affect the health of individuals and their communities.

In terms of health equity, the field of health justice concentrates on interventions and system change that will improve the health and well-being of groups who often have the most complex health and legal needs. These are the people who may be the hardest but most important to reach if historic patterns of disadvantage and damage are ever to be disrupted.

\footnotetext{
${ }^{127}$ E Tobin-Tyler and J Teitelbaum, Essentials of Health Justice (Jones \& Bartlett Learning 2019) x.

${ }^{128}$ Public health law is the study of the legal powers and duties of the state to assure the conditions for people to be healthy (e.g., to identify, prevent, and ameliorate risks to health in that population) and the limitations on the power of the state to constrain the autonomy, privacy, liberty, or other legally protected interests of individuals for the protection and promotion of community health. See S Burris, ML Berman, M Penn and T Ramanathan Holiday, The New Public Health Law: A Transdisciplinary Approach to Practice and Advocacy (OUP 2018$) 4$. ${ }^{129}$ Burris and others (n 10) 139.
} 
The more targeted focus of the health justice field on practice innovation aimed specifically at disadvantaged and vulnerable groups chimes well with Michael Marmot's concept of 'proportionate universalism'. This requires that the scale and intensity of interventions designed to reduce health inequalities should be proportionate to the level of disadvantage. ${ }^{130}$

The ambition of the field of health justice is to promote evidence-based service innovation to better meet the challenge of health inequalities. This requires rigorous transdisciplinary research that draws on the theoretical insights, perspectives, and methods of disciplines such as empirical legal studies, social-epidemiology, sociology, criminology, psychology, and health economics. While evaluating integrated health and legal services is a central element in the scope of health justice, it may be only one part of the field.

\section{B. Transdisciplinary Health Justice Research Opportunities}

It is no longer sustainable for the NHS to focus on fix and repair. There needs to be a major policy shift towards prevention, attuning the NHS budget towards tackling the causes of ill health. We are in the middle of the biggest movement in the world for taking a system of healthcare and turning it into a more integrated model. ${ }^{131}$

Despite the evident benefit of legal services to disadvantaged individuals battling with legal problems, the legal sector and legal academy have paid less attention than the health sector to demonstrating the value of their services. Notwithstanding the need to show that legal aid and other public funding of legal services is money well spent, service providers have not routinely captured information about outcomes that would support objective evaluation. Consequently, in times of constrained public expenditure, the legal services sector has been at a pronounced disadvantage in advocating policies to support or expand public funding for legal services. It has been persuasively argued that the legal services field has much to learn from health services in terms of how to measure the impact and quality of services, how to use data to anticipate and respond to trends, and how best to invest in legal interventions that focus on prevention. ${ }^{132}$

While the population health field has developed sophisticated methodologies for evaluation, there is nonetheless mounting pressure for more and better multi-disciplinary research involving behavioural and social sciences to provide the evidence base for reform of the delivery of healthcare to achieve conspicuous improvements in health and well-being. This requires a greater focus on prevention and on understanding exactly how upstream social, legal, economic and environmental factors affect downstream health - in other words a greater understanding of the complex interactions involved in the pathways between social determinants and health. ${ }^{133}$ The Academy of Medical Sciences has recently argued the need for transdisciplinary approaches to improving population health, creating new knowledge

\footnotetext{
${ }^{130}$ Marmot, Fair Society (n 62).

${ }^{131}$ Sir Malcolm Grant, Chairman NHS England, Health Justice Partnerships in Social Prescribing International Workshop: Full Event Report (Centre for Access to Justice 2017) <www.ucl.ac.uk/access-to-justice/sites/accessto-

justice/files/health_justice_partnerships_international_workshop_november_2017_report_of_discussion_1.pdf> accessed 3 March 2019, 3.

${ }^{132}$ EM Lawton, 'Integrating Healthcare and Legal Services to optimise Health and Justice for Vulnerable Populations: The Global Opportunity' in S Muller, S Zouridis, M Frishman and L Kistemaker (eds), The Law of the Future and the Future of Law: Volume II (Torkel Opsahl Academic EPublisher 2012) 76.

${ }^{133}$ Campaign for Social Science, The Health Of The People: How The Social Sciences Can Improve Population Health (Sage 2017) <https://campaignforsocialscience.org.uk/healthofpeople/> accessed 3 March 2019.
} 
through sharing of different disciplinary methods, theories and knowledge. ${ }^{134}$ The Campaign for Social Science similarly reasons that incorporating robust social science evidence and methods into the development and delivery of health and social interventions would contribute to a more 'complete' strategy for improving health and wellbeing. ${ }^{135}$

Health justice research presents a promising opportunity to advance a pioneering transdisciplinary research agenda. It has the potential to strengthen both public health and access to justice research moving beyond the limitations of single discipline approaches to provide evidence about how health and legal services together might mitigate negative determinants of ill health among disadvantaged and vulnerable groups.It offers the opportunity to evaluate legal assistance as a health intervention. To achieve this level of transdisciplinary collaboration, however, there is a need for health researchers to recognise the importance of law and legal services as influences on health and incorporate that perspective in research. Equally, legal scholars need to appreciate that 'health is one of the most important things that law can influence and that empirical research on law's impact on health makes an important contribution to legal scholarship'. ${ }^{136}$ Through such collaboration, health researchers could understand the ways in which law and legal services influence health, while legal researchers could benefit from exposure to the rigorous evaluation methods and use of large-scale robust data employed by population health researchers. ${ }^{137}$

Efforts to enrich the health justice evidence base are gathering pace through growing international interest in HJP and the strategic work of international organisations such as the US National Center for Medical-Legal Partnership ${ }^{138}$ and Health Justice Australia ${ }^{139}$ who are encouraging theoretical development and greater sophistication in research methodology. The number of studies, including random control trials, is increasing as public health researchers pay attention to the ways in which legal services can address the health effects of poverty and other forms of disadvantage. ${ }^{140}$

There remains a need for robust outcomes-based research demonstrating how integrated health and legal services may impact individual and community health, the work of health and legal professionals, and institutional practices. Areas ripe for exploration include analysis of different HJP models and their relative effectiveness. What types of collaboration work best for which types of service users and which types of legal problems? Do integrated legal and health services deliver wellbeing benefits for disadvantaged and vulnerable groups that go beyond existing service arrangements by preventing the risk of transition into or exacerbation of poor health? Does HJP enable early intervention that could shorten or avoid adverse childhood events thus delivering life course benefits? What is the value of social welfare legal support delivered in association with health services as compared with the health benefits of social welfare legal services delivered in other settings? What are the costs of not

\footnotetext{
${ }^{134}$ Academy of Medical Sciences, Improving The Health of The Public By 2040 (Academy of Medical Sciences 2016) <https://acmedsci.ac.uk/file-download/41399-5807581429f81.pdf> accessed 3 March 2019.

135 cf Campaign for Social Science (n 134) 5.

${ }^{136}$ S Burris, 'From Health Care Law to The Social Determinants of Health: A Public Health Law Research Perspective' (2011) 159 University of Pennsylvania Law Review 1649, 1666-7.

137 cf Lawton (n 132) 77.

${ }^{138}$ See homepage: <https://medical-legalpartnership.org/> accessed 27 March 2019.

${ }^{139}$ See homepage: <https://www.healthjustice.org.au/> accessed 27 March 2019.

${ }^{140}$ For example, D Howel, S Moffatt, C Haighton, A Bryant, F Becker and others 'Does domiciliary welfare rights advice improve health-related quality of life in independent-living, socio-economically disadvantaged people aged $\geq 60$ years? Randomised controlled trial, economic and process evaluations in the North East of England' (2019) 14(1) PLOS ONE <https://doi.org/10.1371/journal.pone.0209560> accessed 27 March 2019; M Sandel, 'Housing Prescription as Health Care', Clinical Trial, Boston Medical Center <https://clinicaltrials.gov/ct2/show/study/NCT02816294> accessed 3 March 2019, study in progress due to be completed December 2020.
} 
addressing legal needs? These are just a few of the questions that require investigation to support the development of evidence-based and effective policy and practice. The developing policy environment, stressing prevention-focused service innovation that involves collaboration with other services and professions, presents unprecedented opportunities for experimentation and investigation of the connection between law, health and well-being.

\section{Health Justice Policy Development Opportunities}

Everybody actually knows that making the population healthy is not delivered through the NHS; it is delivered through almost everything else. ${ }^{141}$

Britain is not alone in having an underwhelming history of cross-government collaboration in the development of public health policy or, indeed, in a range of other policy areas. Traditional vertical departmental silos have hindered horizontal coordination. While the need for 'joinedup thinking' in tackling cross-sector social problems has been recognised by successive governments, most notably the late-1990s Labour Government's campaign of 'joined up government' (JUG), real progress in this respect has been difficult to achieve. Several factors are said to inhibit cross-departmental collaboration, for example, the tendency to view problems from the perspective of service providers rather than service users; the absence of tangible incentives or reward for contributing to the goals of another department (why spend legal aid money to save money from the health budget and vice versa?); budgets and organisational structures that are arranged around vertical, functional lines (such as education, health, defence etc) rather than horizontal, cross-cutting problems and issues (such as health inequalities or social exclusion). It is also suggested that a culture of risk aversion within departments militates against innovative cross-cutting working. ${ }^{142}$

Regardless of these challenges, it is uncontroversial to say that improving public health and reducing health inequalities demands multi-departmental collaborative thinking and action. At the highest policy level, the language of cross sector working has been around for at least two decades. In 2002 a Cross-Cutting Review for tackling health inequalities, ${ }^{143}$ involving around twenty representatives from government departments and units, concluded that the way forward was to 'mainstream' work on health inequalities 'so that it is at the heart of Government policies rather than a marginal "add on"". ${ }^{144}$ The recommendation was for partnership, across Government and between Government and local communities. The Lord Chancellor's Department (then responsible for legal aid and access to justice now MOJ) was not included in the review.

The establishment in 2010 and then abolition only two years later of a cross department Cabinet Sub-Committee on Public Health - created precisely to promote cross-departmental thinking - does not immediately inspire confidence. The Sub-Committee, chaired by the Secretary of State for Health, was regarded by the Health Select Committee of the time as a 'significant step forward in developing a much-needed cross-departmental approach to public health'. It brought together 19 cabinet ministers and junior ministers from 13 government

\footnotetext{
${ }^{141}$ Andrew Lansley, former Health Minister, in N Timmins and E Davies, Glaziers \& Window breakers: The Role of the Secretary of State for Health, In Their Own Words (The Health Foundation 2015) 157.

${ }^{142}$ Cabinet Office Performance and Innovation Unit, Wiring It Up: Whitehall's Management of Cross-cutting Policies and Services (The Stationary Office 2000).

143 Department of Health, Tackling Health Inequalities: 2002 Cross-Cutting Review (November 2002) <https://webarchive.nationalarchives.gov.uk/20110321235115/http://www.dh.gov.uk/en/publicationsandstatistic s/publications/publicationspolicyandguidance/dh_4098280> accessed 27 March 2019.

144 ibid 3, para 9.
} 
departments and the Cabinet Office. The vision was that progress might be made on public health improvement by co-ordinating related policy areas such as sport, families and transport with that of the health department. (Notably absent again was any representative from the Ministry of Justice.) It seems that the Committee struggled to engage representatives from departments other than health and was abandoned in 2012. ${ }^{145}$

Despite this failure, I would suggest that with the intensified focus on prevention and partnership to tackle health inequalities spelled out in the NHS Long Term Plan for England \& Wales in 2019, we could be at a turning point. The movement for social prescribing has been gaining increasing attention, supported by the Royal College of GPs (RCGP), NHS England, and the Department of Health and Social Care. In its promotion of integrated health, ${ }^{146}$ collaboration and partnership, the 2019 NHS Long Term Plan pledges to roll out GP social prescribing across England so that by $2023 / 24$ some 900,000 people can be referred to through social prescribing schemes. There are also important local initiatives such as the Mayor of London's Inequalities Strategy which proposes that social prescribing should become a routine part of community support across London. Although many of the policy documents are short on specifics, Healthy London Partnerships are developing a social prescribing vision for London which includes social welfare legal services as one of their four key areas of focus. ${ }^{147}$ There is some appreciation at national level that social prescribing should recognize a hierarchy of need in which the most urgent needs of patients - such as safety, financial security and housing - must be addressed before other initiatives can work. ${ }^{148}$ This situates social welfare legal services as a central element in social prescribing.

One critical weakness in the policy of promoting social prescribing, however, is the lack of an obvious funding stream that would support the community-based services on which social prescribing depends. Many of the services to which patients are referred through social prescription 'link workers' are provided free by community-based organizations depending on fragmented financial support and the labour of volunteers. As far as social welfare legal services are concerned, we have seen that most have very fragile funding and a question mark hangs over survival, let alone capacity to increase throughput. If social prescribing is to be central in the delivery of health and social care services in the future, the question arises as to how the community and neighbourhood assets - the foundation of social prescribing - are to be maintained and grown. Long-term sustainability requires active engagement and commitment of resource from across government.

\footnotetext{
${ }^{145}$ D Buck, 'The Passing of The Public Health Sub-Committee: Mourning A Missed Opportunity' (The King's Fund Blog, 21 November 2012) <www.kingsfund.org.uk/blog/2012/11/passing-public-health-sub-committeemourning-missed-opportunity> accessed 3 March 2019; D Campbell, 'Doctors Dismayed As Public Health $\begin{array}{lllllll}\text { Committee Is } \quad \text { Scrapped' } & \text { The } & \text { Guardian } & \text { (8) }\end{array}$ <//www.theguardian.com/politics/2012/nov/08/doctors-dismay-public-health-committee> accessed 3 March 2019.

${ }^{146}$ The aim of integrated health is being pursued through sustainability and transformation partnerships (STPs) charged with developing new models of care. The vision of joined up, person-centred care is the new culture to which social prescribing belongs. STPs have no basis in legislation, and rest on the willingness and commitment of organisations and leaders to work collaboratively.

147 Healthy London Partnership, Social Prescribing: Our Vision for London 2018-2028 Improving Lives, Improving Health (December 2018) <www.healthylondon.org/wp-content/uploads/2018/12/2018-03-2018Social-prescribing-Our-vision-for-London-2018-2028-v0.01.pdf > accessed 3 March 2019, 22.

${ }^{148}$ See comments by Bev Taylor, Senior Choice Manager - Social Prescribing, NHS England, in Health Justice Partnerships in Social Prescribing International Workshop: Full Event Report (Centre for Access to Justice 2017) $<$ www.ucl.ac.uk/access-to-justice/sites/access-tojustice/files/health_justice_partnerships_international_workshop_november_2017_report_of_discussion_1.pdf> accessed 3 March 2019, 3.
} 
In an interesting and apparently independent policy initiative, the Ministry of Justice is now promoting integration between health and legal services to avoid the health-harming effects of unmet legal need. ${ }^{149}$ Following its review of LASPO, the Ministry of Justice announced in February 2019 that it intends to make available funding for legal services in GP surgeries. This is a small step in the direction of more joined-up thinking and could, possibly, be a catalyst for wider cross-government collaboration. To seize this moment, however, there is a need to capture the attention of the many other departments whose policies and decisionmaking determine health and for courageous policy 'entrepreneurs' to begin to build crosssector relationship. ${ }^{150}$

Good health is an asset that is necessary for a flourishing society. Improving population health not only enhances lives and resilience but serves broader societal and economic ambitions of strengthening the productivity of the workforce and creating a prosperous society. Investment in the health of the public should be regarded as a cross-government priority rather than limited to the concerns of the Department of Health. ${ }^{151}$

\section{Conclusion}

As the legal sector seeks to find ways of alleviating the crisis in access to justice and the health sector struggles to reduce health inequalities, an understanding of the link between law and health offers some opportunities in both fields of endeavour. Many social determinants of health manifest at community and individual level as legal needs, or as social needs with legal dimensions. ${ }^{152}$ Unmet legal needs in the form of adverse social conditions with a legal remedy are social determinants of health.

This article has described the extent to which the importance of law and legal services to health and well-being has been experientially understood by many community legal and health practitioners even though, to date, largely overlooked in social determinants of health discourse, policy and research. Health justice partnership is a practitioner-led movement that promotes an integrated services approach to address the root causes of ill health rather than merely treating the physical and psychological manifestations of negative social determinants of health. Health justice partnership is grounded in an understanding of the bidirectional link between law and health and, within an integrated care framework, responds to the complex legal and health needs of many disadvantaged individuals and communities. It advances the prevention agenda in both law and health, reaching people at an early stage and those who may not recognise a social or health problem as capable of legal remedy.

Empowering disadvantaged and vulnerable people to secure the services and protections to which they are entitled is both just and functional to the extent that their situation and life experience may be improved and that eventually, cycles of deprivation could be disrupted. At a broader level, lawyers and health professionals working in partnership can

\footnotetext{
${ }^{149}$ Ministry of Justice, Legal Support: The Way Ahead: An Action Plan to Deliver Better Support to People $\begin{array}{lllll}\text { Experiencing Legal Problems } & \text { (CP } & \text { 40, }\end{array}$ <https://assets.publishing.service.gov.uk/government/uploads/system/uploads/attachment_data/file/777036/legal -support-the-way-ahead.pdf> accessed 27 March 2019, 24.

${ }^{150}$ M Exworthy, D Blane and M Marmot, 'Tackling Health Inequalities in the United Kingdom: The Progress and Pitfalls of Policy' (2003) 38 Health Serv Res 1905, 1918.

${ }^{151}$ J Bibby and E Spencelayh, 'Could Government Do More to Consider the Impact on Health of Wider Policy?' in A Healthier Life for All: The Case for Cross-Government Action (The All-Party Parliamentary Health Group and The Health Foundation 2016).

${ }^{152}$ B Castrucci and J Auerbach, 'Meeting Individual Social Needs Falls Short of Addressing Social Determinants of Health' (Health Affairs Blog, $16 \quad$ January $16 \quad$ 2019) <https://www.healthaffairs.org/do/10.1377/hblog20190115.234942/full/> accessed 3 March 2019.
} 
reveal failures in policy implementation and enforcement highlighting gaps between law on the books and the law in action - what should be fertile territory for socio-legal research focused on health. While effective access to justice is fundamental to the rule of law, it is not an end in itself. It facilitates the enforcement of rights and entitlements prescribed by law and in so doing promotes well-being in the widest sense of the word.

In describing the field of health justice and the practice of health justice partnership, this article argues for recognition of the potential for appropriately integrating legal and health services, for better research to understand the individual, community, population and system benefits of integrating legal and health services and for policy coordination that acknowledges shared responsibility across government for improving the health of the public. 